\title{
Activation of 1,1-Difluoro-1-alkenes with Transition-Metal Complex: Palladium(II)-Catalyzed Friedel-Crafts-Type Cyclization of 4,4-(Difluorohomoallyl)arenes
}

\author{
Misaki Yokota, ${ }^{\star}$ Daishi Fujita, ${ }^{\ddagger}$ and Junji Ichikawa* ${ }^{\dagger}$ \\ $\dagger$ Department of Chemistry, Graduate School of Pure and Applied Sciences, University of Tsukuba, \\ Tsukuba, Ibaraki 305-8571, Japan \\ $¥$ Department of Chemistry, Graduate School of Science, The University of Tokyo, Hongo, \\ Bunkyo-ku, Tokyo 113-0033, Japan
}

\section{Supporting Information}

General: NMR spectra were obtained on JEOL AL 400, Bruker DRX 500, or Bruker AVANCE 500 spectrometers at the indicated field strengths. Chemical shift values were given in ppm relative to internal $\mathrm{Me}_{4} \mathrm{Si}$ (for ${ }^{1} \mathrm{H}$ NMR: $\delta 0.00$ ), $\mathrm{CDCl}_{3}$ (for ${ }^{13} \mathrm{C}$ NMR: $\delta 77.0$ ), and $\mathrm{C}_{6} \mathrm{~F}_{6}$ (for ${ }^{19} \mathrm{~F} \mathrm{NMR:} \delta 0.00$ ). IR spectra were recorded on a Horiba FT $300 \mathrm{~S}$ by ATR method. High-resolution mass spectra were obtained with a JEOL MS-700P mass spectrometer. Elemental analyses were carried out at The Elemental Analysis Laboratory, Department of Chemistry, Faculty of Science, The University of Tokyo. Tetrahydrofuran (THF) and diethyl ether $\left(\mathrm{Et}_{2} \mathrm{O}\right)$ were purchased from Kanto Chemical Co., Inc. and used without purification. Hexamethylphosphoric triamide (HMPA) was distilled from $\mathrm{CaH}_{2}$, and stored over molecular sieves $4 \AA$. $N, N$-Dimethylformamide (DMF) was dried over $\mathrm{P}_{2} \mathrm{O}_{5}$, then distilled under reduced pressure from $\mathrm{CaH}_{2}$, and stored over molecular sieves $4 \AA$. 1,1,1,3,3,3-Hexafluoropropan-2-ol (HFIP) was distilled from molecular sieves $4 \AA$, and stored over molecular sieves $4 \AA$. Column chromatography and preparative thin-layer chromatography (PTLC) were performed on silica gel (Kanto Chemical Co., Inc., Silica Gel 60 and Wako Pure Chemical Industries, Ltd., B5-F), respectively.

Difluoroalkene 1a-h were prepared from commercially available 2,2,2-trifluoroethyl 4-methylbenzenesulfonate via boron-mediated alkylation (2-arylethylation), followed by protonolysis of difluorovinylboranes. ${ }^{1}$ Dialkyl-substituted difluoroalkene $1 \mathbf{i}$ was prepared by the $\mathrm{S}_{\mathrm{N}} 2^{\prime}$ reaction of 4-phenyl-2-(trifluoromethyl)but-1-ene with butyllithium. ${ }^{2}$

\section{1,1-Difluoro-4-(2-naphthyl)but-1-ene (1a) $)^{3}$}

Butyllithium (13.3 mL, 1.53 M in hexane, $20.4 \mathrm{mmol})$ was added to a THF $(50.0 \mathrm{~mL})$ solution of 2,2,2-trifluoroethyl 4-methylbenzenesulfonate $(2.46 \mathrm{~g}, 9.68 \mathrm{mmol})$ at $-78{ }^{\circ} \mathrm{C}$ over $10 \mathrm{~min}$ under argon. The reaction mixture was stirred for $30 \mathrm{~min}$ at $-78{ }^{\circ} \mathrm{C}$, and then tris[2-(2-naphthyl)ethyl]borane [Borane-THF complex $(11.0 \mathrm{~mL}, 1.08 \mathrm{M}$ in THF, $11.9 \mathrm{mmol})$ was added to a solution of 2-vinylnaphthalene $(5.00 \mathrm{~g}, 32.4 \mathrm{mmol})$ in THF $(10.0 \mathrm{~mL})$ at $0{ }^{\circ} \mathrm{C}$ over $10 \mathrm{~min}$, and the mixture was stirred for $3 \mathrm{~h}$ at room temperature.] was added at $-78{ }^{\circ} \mathrm{C}$ over $30 \mathrm{~min}$. After being stirred for $1 \mathrm{~h}$, the reaction mixture was warmed to room temperature and stirred for an additional $1 \mathrm{~h}$, and then heated at reflux for 
$2 \mathrm{~h}$. The resulting solution was cooled to $0{ }^{\circ} \mathrm{C}$ and treated with HMPA $(12.5 \mathrm{~mL})$ and cuprous iodide $(3.70 \mathrm{~g}, 19.4 \mathrm{mmol})$. After the mixture was stirred for $0.5 \mathrm{~h}$ at room temperature, phosphate buffer $(\mathrm{pH}$ 7) was added to quench the reaction. The mixture was filtered, and organic materials were extracted with $\mathrm{Et}_{2} \mathrm{O}$ three times. The combined extracts were washed with brine and dried over $\mathrm{Na}_{2} \mathrm{SO}_{4}$. After removal of the solvent under reduced pressure, the residue was purified by column chromatography on silica gel (pentane) to give 1a $(1.37 \mathrm{~g}, 65 \%)$ as a colorless liquid. IR (neat): 3054, 2927, 1745, 1600, 1508, 1303, $1222,1162,1012,815,746 \mathrm{~cm}^{-1} .{ }^{1} \mathrm{H}$ NMR $\left(500 \mathrm{MHz}, \mathrm{CDCl}_{3}\right): \delta 2.39\left(2 \mathrm{H}, \mathrm{tddd}, J=7.6,7.6 \mathrm{~Hz}, J_{\mathrm{HF}}=\right.$ $1.8,1.8 \mathrm{~Hz}), 2.84(2 \mathrm{H}, \mathrm{t}, J=7.6 \mathrm{~Hz}), 4.18\left(1 \mathrm{H}, \mathrm{dtd}, J_{\mathrm{HF}}=25.3 \mathrm{~Hz}, J=7.6 \mathrm{~Hz}, J_{\mathrm{HF}}=2.7 \mathrm{~Hz}\right), 7.32(1 \mathrm{H}$, $\mathrm{dd}, J=8.1,1.0 \mathrm{~Hz}), 7.43(1 \mathrm{H}, \mathrm{ddd}, J=8.1,8.1,1.0 \mathrm{~Hz}), 7.45(1 \mathrm{H}, \mathrm{ddd}, J=8.1,8.1,1.0 \mathrm{~Hz}), 7.61(1 \mathrm{H}, \mathrm{d}$, $J=1.0 \mathrm{~Hz}), 7.75(1 \mathrm{H}, \mathrm{d}, J=8.1 \mathrm{~Hz}), 7.75(1 \mathrm{H}, \mathrm{dd}, J=8.1,1.0 \mathrm{~Hz}), 7.80(1 \mathrm{H}, \mathrm{dd}, J=8.1,1.0 \mathrm{~Hz}) .{ }^{13} \mathrm{C}$ $\operatorname{NMR}\left(126 \mathrm{MHz}, \mathrm{CDCl}_{3}\right): \delta 23.9\left(\mathrm{~d}, J_{\mathrm{CF}}=4 \mathrm{~Hz}\right), 35.8\left(\mathrm{~d}, J_{\mathrm{CF}}=2 \mathrm{~Hz}\right), 77.3\left(\mathrm{dd}, J_{\mathrm{CF}}=22,21 \mathrm{~Hz}\right), 125.3$, 126.0, 126.6, 127.1, 127.5, 127.6, 128.0, 132.1, 133.6, 138.4, $156.4\left(\mathrm{dd}, J_{\mathrm{CF}}=288,286 \mathrm{~Hz}\right) .{ }^{19} \mathrm{~F} \mathrm{NMR}$ $\left(470 \mathrm{MHz}, \mathrm{CDCl}_{3}\right): \delta 70.9\left(1 \mathrm{~F}, \mathrm{ddt}, J_{\mathrm{FF}}=47 \mathrm{~Hz}, J_{\mathrm{FH}}=25,2 \mathrm{~Hz}\right), 72.9\left(1 \mathrm{~F}\right.$, br d, $\left.J_{\mathrm{FF}}=47 \mathrm{~Hz}\right)$. Anal. Calcd for $\mathrm{C}_{14} \mathrm{H}_{12} \mathrm{~F}_{2}$ : C, 77.05; H, 5.54. Found: C, 77.26; H, 5.76.

\section{1,1-Difluoro-4-phenylbut-1-ene (1b) ${ }^{3}$}

Compound 1b was prepared by the method described for 1a. IR (neat): 3026, 2926, 1736, 1603, 1493, $1450,1375,1028,760,700 \mathrm{~cm}^{-1} .{ }^{1} \mathrm{H}$ NMR $\left(500 \mathrm{MHz}, \mathrm{CDCl}_{3}\right): \delta 2.29\left(2 \mathrm{H}, \mathrm{tddd}, J=7.6,7.6 \mathrm{~Hz}, J_{\mathrm{HF}}=\right.$ $1.5,1.5 \mathrm{~Hz}), 2.68(2 \mathrm{H}, \mathrm{t}, J=7.6 \mathrm{~Hz}), 4.15\left(1 \mathrm{H}, \mathrm{dtd}, J_{\mathrm{HF}}=24.1 \mathrm{~Hz}, J=7.6 \mathrm{~Hz}, J_{\mathrm{HF}}=2.4 \mathrm{~Hz}\right), 7.16-7.22$ $(3 \mathrm{H}, \mathrm{m}), 7.29(2 \mathrm{H}, \mathrm{t}, J=7.6 \mathrm{~Hz}) \cdot{ }^{13} \mathrm{C} \mathrm{NMR}\left(126 \mathrm{MHz}, \mathrm{CDCl}_{3}\right): \delta 24.1\left(\mathrm{~d}, J_{\mathrm{CF}}=4 \mathrm{~Hz}\right), 35.7\left(\mathrm{~d}, J_{\mathrm{CF}}=2\right.$ $\mathrm{Hz}), 77.3\left(\mathrm{dd}, J_{\mathrm{CF}}=22,22 \mathrm{~Hz}\right), 126.1,128.4,128.4,141.0,156.3\left(\mathrm{dd}, J_{\mathrm{CF}}=287,287 \mathrm{~Hz}\right) .{ }^{19} \mathrm{~F} \mathrm{NMR}$ $\left(470 \mathrm{MHz}, \mathrm{CDCl}_{3}\right): \delta 70.7\left(1 \mathrm{~F}, \mathrm{ddt}, J_{\mathrm{FF}}=47 \mathrm{~Hz}, J_{\mathrm{FH}}=24,2 \mathrm{~Hz}\right), 72.7\left(1 \mathrm{~F}\right.$, br d, $\left.J_{\mathrm{FF}}=47 \mathrm{~Hz}\right)$. Anal. Calcd for $\mathrm{C}_{10} \mathrm{H}_{10} \mathrm{~F}_{2}$ : C, 71.41; H, 5.99. Found: C, 71.62; H, 6.24.

\section{1,1-Difluoro-4-phenylpent-1-ene (1c) ${ }^{3}$}

Compound 1c was prepared by the method described for 1a. IR (neat): 3152, 3095, 1778, 1528, 1482, 1205, 788, $723 \mathrm{~cm}^{-1} .{ }^{1} \mathrm{H}$ NMR (400 MHz, $\left.\mathrm{CDCl}_{3}\right): \delta 1.27(3 \mathrm{H}, \mathrm{d}, J=7.1 \mathrm{~Hz}), 2.24(2 \mathrm{H}$, dddd, $J=7.8$, $\left.7.4 \mathrm{~Hz}, J_{\mathrm{HF}}=1.9,1.9 \mathrm{~Hz}\right), 2.75(1 \mathrm{H}, \mathrm{tq}, J=7.4,7.1 \mathrm{~Hz}), 4.04\left(1 \mathrm{H}, \mathrm{dtd}, J_{\mathrm{HF}}=25.6 \mathrm{~Hz}, J=7.8 \mathrm{~Hz}, J_{\mathrm{HF}}=\right.$ $2.6 \mathrm{~Hz}), 7.16-7.22(3 \mathrm{H}, \mathrm{m}), 7.29(2 \mathrm{H}, \mathrm{dd}, J=7.4,7.4 \mathrm{~Hz}) .{ }^{13} \mathrm{C} \mathrm{NMR}\left(126 \mathrm{MHz}, \mathrm{CDCl}_{3}\right): \delta 21.2,30.9(\mathrm{~d}$, $\left.J_{\mathrm{CF}}=4 \mathrm{~Hz}\right), 39.8\left(\mathrm{dd}, J_{\mathrm{CF}}=2,2 \mathrm{~Hz}\right), 76.4\left(\mathrm{dd}, J_{\mathrm{CF}}=22,21 \mathrm{~Hz}\right), 126.2,126.9,128.4,146.0,156.5(\mathrm{dd}$,

$\left.J_{\mathrm{CF}}=287,285 \mathrm{~Hz}\right) .{ }^{19} \mathrm{~F} \mathrm{NMR}\left(376 \mathrm{MHz}, \mathrm{CDCl}_{3}\right): \delta 70.2\left(1 \mathrm{~F}, \mathrm{dd}, J_{\mathrm{FF}}=46 \mathrm{~Hz}, J_{\mathrm{FH}}=26 \mathrm{~Hz}\right), 72.6(1 \mathrm{~F}, \mathrm{dd}$, $J_{\mathrm{FF}}=46 \mathrm{~Hz}, J_{\mathrm{FH}}=3 \mathrm{~Hz}$ ). Anal. Calcd for $\mathrm{C}_{11} \mathrm{H}_{12} \mathrm{~F}_{2}: \mathrm{C}, 72.51 ; \mathrm{H}, 6.64$. Found: C, 72.67; H, 6.80.

\section{1,1-Difluoro-4-(4-methylphenyl)pent-1-ene (1d)}

Compound 1d was prepared by the method described for 1a. IR (neat): 2962, 1743, 1516, 1456, 1306, 1232, 1173, 1049, 1007, $721 \mathrm{~cm}^{-1} .{ }^{1} \mathrm{H}$ NMR (500 MHz, $\left.\mathrm{CDCl}_{3}\right): \delta 1.25(3 \mathrm{H}, \mathrm{d}, J=7.1 \mathrm{~Hz}), 2.22(2 \mathrm{H}$, dddd, $\left.J=7.8,7.4 \mathrm{~Hz}, J_{\mathrm{HF}}=1.8,1.8 \mathrm{~Hz}\right), 2.32(3 \mathrm{H}, \mathrm{s}), 2.72(1 \mathrm{H}, \mathrm{tq}, J=7.4,7.1 \mathrm{~Hz}), 4.04\left(1 \mathrm{H}, \mathrm{dtd}, J_{\mathrm{HF}}=\right.$ $\left.25.4 \mathrm{~Hz}, J=7.8 \mathrm{~Hz}, J_{\mathrm{HF}}=2.6 \mathrm{~Hz}\right), 7.29(2 \mathrm{H}, \mathrm{d}, J=8.1 \mathrm{~Hz}), 7.11(2 \mathrm{H}, \mathrm{d}, J=8.1 \mathrm{~Hz}) .{ }^{13} \mathrm{C}$ NMR $(126$ $\left.\mathrm{MHz}, \mathrm{CDCl}_{3}\right): \delta 21.0,21.4,30.9\left(\mathrm{~d}, J_{\mathrm{CF}}=4 \mathrm{~Hz}\right), 39.4\left(\mathrm{dd}, J_{\mathrm{CF}}=3,2 \mathrm{~Hz}\right), 76.5\left(\mathrm{dd}, J_{\mathrm{CF}}=22,21 \mathrm{~Hz}\right)$, 126.7, 129.1, 135.7, 143.0, $156.4\left(\mathrm{dd}, J_{\mathrm{CF}}=287,285 \mathrm{~Hz}\right) .{ }^{19} \mathrm{~F}$ NMR $\left(376 \mathrm{MHz}, \mathrm{CDCl}_{3}\right): \delta 70.1(1 \mathrm{~F}, \mathrm{dd}$, $\left.J_{\mathrm{FF}}=47 \mathrm{~Hz}, J_{\mathrm{FH}}=25 \mathrm{~Hz}\right), 72.5\left(1 \mathrm{~F}, \mathrm{dd}, J_{\mathrm{FF}}=47 \mathrm{~Hz}, J_{\mathrm{FH}}=3 \mathrm{~Hz}\right)$. Anal. Calcd for $\mathrm{C}_{12} \mathrm{H}_{14} \mathrm{~F}_{2}: \mathrm{C}, 73.45 ; \mathrm{H}$, 
7.19. Found: $\mathrm{C}, 73.42 ; \mathrm{H}, 7.31$.

\section{1,1-Difluoro-4-(4-methoxyphenyl)pent-1-ene (1e)}

Compound 1e was prepared by the method described for 1a. IR (neat): 2960, 1745, 1614, 1512, 1458, 1298, 1248, 1178, 1039, $829 \mathrm{~cm}^{-1} .{ }^{1} \mathrm{H}$ NMR (400 MHz, $\left.\mathrm{CDCl}_{3}\right): \delta 1.24(3 \mathrm{H}, \mathrm{d}, J=7.1 \mathrm{~Hz}), 2.21(2 \mathrm{H}$, dddd, $\left.J=7.8,7.4 \mathrm{~Hz}, J_{\mathrm{HF}}=1.8,1.8 \mathrm{~Hz}\right), 2.71(1 \mathrm{H}, \mathrm{tq}, J=7.4,7.1 \mathrm{~Hz}), 3.79(3 \mathrm{H}, \mathrm{s}), 4.03\left(1 \mathrm{H}, \mathrm{dtd}, J_{\mathrm{HF}}=\right.$ $\left.25.5 \mathrm{~Hz}, J=7.8 \mathrm{~Hz}, J_{\mathrm{HF}}=2.6 \mathrm{~Hz}\right), 6.84(2 \mathrm{H}, \mathrm{d}, J=8.7 \mathrm{~Hz}), 7.09(2 \mathrm{H}, \mathrm{d}, J=8.7 \mathrm{~Hz}) .{ }^{13} \mathrm{C} \mathrm{NMR}(101$ $\left.\mathrm{MHz}, \mathrm{CDCl}_{3}\right): \delta 21.5,31.1\left(\mathrm{~d}, J_{\mathrm{CF}}=3 \mathrm{~Hz}\right), 39.0\left(\mathrm{dd}, J_{\mathrm{CF}}=2,2 \mathrm{~Hz}\right), 55.3,76.5\left(\mathrm{dd}, J_{\mathrm{CF}}=22,21 \mathrm{~Hz}\right)$, 113.7, 127.7, 138.1, $156.3\left(\mathrm{dd}, J_{\mathrm{CF}}=286,285 \mathrm{~Hz}\right), 157.9 .{ }^{19} \mathrm{~F}$ NMR $\left(376 \mathrm{MHz}, \mathrm{CDCl}_{3}\right): \delta 70.1(1 \mathrm{~F}, \mathrm{dd}$, $\left.J_{\mathrm{FF}}=47 \mathrm{~Hz}, J_{\mathrm{FH}}=26 \mathrm{~Hz}\right), 72.5\left(1 \mathrm{~F}\right.$, br d, $\left.J_{\mathrm{FF}}=47 \mathrm{~Hz}\right)$. Anal. Calcd for $\mathrm{C}_{12} \mathrm{H}_{14} \mathrm{~F}_{2} \mathrm{O}: \mathrm{C}, 67.91 ; \mathrm{H}, 6.65$. Found: C, 67.95; H, 6.76.

\section{1,1-Difluoro-4-(3-methoxyphenyl)pent-1-ene (1f)}

Compound 1f was prepared by the method described for 1a. IR (neat): 2962, 1743, 1583, 1487, 1230, 1157, 1043, 920, 777, $698 \mathrm{~cm}^{-1} .{ }^{1} \mathrm{H}$ NMR (400 MHz, $\left.\mathrm{CDCl}_{3}\right): \delta 1.26(3 \mathrm{H}, \mathrm{d}, J=7.0 \mathrm{~Hz}), 2.24(2 \mathrm{H}$, dddd, $\left.J=7.9,7.3 \mathrm{~Hz}, J_{\mathrm{HF}}=1.8,1.8 \mathrm{~Hz}\right), 2.73(1 \mathrm{H}, \mathrm{tq}, J=7.3,7.0 \mathrm{~Hz}), 3.80(3 \mathrm{H}, \mathrm{s}), 4.04\left(1 \mathrm{H}, \mathrm{dtd}, J_{\mathrm{HF}}=25.4\right.$ $\left.\mathrm{Hz}, J=7.9 \mathrm{~Hz}, J_{\mathrm{HF}}=2.6 \mathrm{~Hz}\right), 6.71-6.79(3 \mathrm{H}, \mathrm{m}), 7.22(1 \mathrm{H}, \mathrm{dd}, J=7.8,7.8 \mathrm{~Hz}) .{ }^{13} \mathrm{C} \mathrm{NMR}(101 \mathrm{MHz}$, $\left.\mathrm{CDCl}_{3}\right): \delta 21.3,30.8\left(\mathrm{~d}, J_{\mathrm{CF}}=4 \mathrm{~Hz}\right), 39.9\left(\mathrm{dd}, J_{\mathrm{CF}}=2,2 \mathrm{~Hz}\right), 55.2,76.4\left(\mathrm{dd}, J_{\mathrm{CF}}=22,21 \mathrm{~Hz}\right), 111.1$, $112.9,119.3,129.3,147.7,156.4\left(\mathrm{dd}, J_{\mathrm{CF}}=287,285 \mathrm{~Hz}\right), 159.6 .{ }^{19} \mathrm{~F}$ NMR $\left(376 \mathrm{MHz}, \mathrm{CDCl}_{3}\right): \delta 70.2$ $\left(1 \mathrm{~F}, \mathrm{dd}, J_{\mathrm{FF}}=47 \mathrm{~Hz}, J_{\mathrm{FH}}=25 \mathrm{~Hz}\right), 72.6\left(1 \mathrm{~F}, \mathrm{br} \mathrm{d}, J_{\mathrm{FF}}=47 \mathrm{~Hz}\right)$. Anal. Calcd for $\mathrm{C}_{12} \mathrm{H}_{14} \mathrm{~F}_{2} \mathrm{O}: \mathrm{C}, 67.91 ; \mathrm{H}$, 6.65. Found: C, 67.80; H, 6.84 .

\section{4-(5,5-Difluoropent-4-en-2-yl)phenol (1g)}

Compound 1g was prepared by the method described for 1a. IR (neat): 3324, 1743, 1612, 1599, 1514, 1230, 1173, 1049, 1007, $829 \mathrm{~cm}^{-1} .{ }^{1} \mathrm{H}$ NMR $\left(500 \mathrm{MHz}, \mathrm{CDCl}_{3}\right): \delta 1.23(3 \mathrm{H}, \mathrm{d}, J=7.0 \mathrm{~Hz}), 2.20(2 \mathrm{H}$, dddd, $\left.J=7.8,7.4 \mathrm{~Hz}, J_{\mathrm{HF}}=1.8,1.8 \mathrm{~Hz}\right), 2.70(1 \mathrm{H}, \mathrm{tq}, J=7.4,7.0 \mathrm{~Hz}), 4.02\left(1 \mathrm{H}, \mathrm{dtd}, J_{\mathrm{HF}}=25.5 \mathrm{~Hz}, J=\right.$ $\left.7.8 \mathrm{~Hz}, J_{\mathrm{HF}}=2.6 \mathrm{~Hz}\right), 4.66(1 \mathrm{H}, \mathrm{s}), 6.77(2 \mathrm{H}, \mathrm{d}, J=8.5 \mathrm{~Hz}), 7.05(2 \mathrm{H}, \mathrm{d}, J=8.5 \mathrm{~Hz}) .{ }^{13} \mathrm{C} \mathrm{NMR}(126$ $\left.\mathrm{MHz}, \mathrm{CDCl}_{3}\right): \delta 21.4,30.0\left(\mathrm{~d}, J_{\mathrm{CF}}=4 \mathrm{~Hz}\right), 39.0\left(\mathrm{dd}, J_{\mathrm{CF}}=2,2 \mathrm{~Hz}\right), 76.4\left(\mathrm{dd}, J_{\mathrm{CF}}=22,21 \mathrm{~Hz}\right), 115.2$, $128.0,138.3,153.8,156.4\left(\mathrm{dd}, J_{\mathrm{CF}}=287,285 \mathrm{~Hz}\right) .{ }^{19} \mathrm{~F} \mathrm{NMR}\left(376 \mathrm{MHz}, \mathrm{CDCl}_{3}\right): \delta 70.1\left(1 \mathrm{~F}, \mathrm{dd}, J_{\mathrm{FF}}=\right.$ $\left.47 \mathrm{~Hz}, J_{\mathrm{FH}}=26 \mathrm{~Hz}\right), 72.5\left(1 \mathrm{~F}\right.$, br d, $\left.J_{\mathrm{FF}}=47 \mathrm{~Hz}\right)$. HRMS $(\mathrm{FAB}): \mathrm{m} / z$ calcd for $\mathrm{C}_{11} \mathrm{H}_{13} \mathrm{~F}_{2} \mathrm{O}\left([\mathrm{M}+\mathrm{H}]^{+}\right)$: 199.0935; found: 199.0942 .

\section{1,1-Difluoro-4-(4-trifluoromethylphenyl)pent-1-ene (1h)}

Compound $\mathbf{1 h}$ was prepared by the method described for 1a. IR (neat): 2968, 1745, 1620, 1458, 1419, 1323, 1117, 1068, 1014, $837 \mathrm{~cm}^{-1} .{ }^{1} \mathrm{H}$ NMR $\left(500 \mathrm{MHz}, \mathrm{CDCl}_{3}\right): \delta 1.29(3 \mathrm{H}, \mathrm{d}, J=7.0 \mathrm{~Hz}), 2.26(2 \mathrm{H}$, dddd, $\left.J=7.8,7.4 \mathrm{~Hz}, J_{\mathrm{HF}}=1.7,1.7 \mathrm{~Hz}\right), 2.83(1 \mathrm{H}, \mathrm{tq}, J=7.4,7.0 \mathrm{~Hz}), 4.02\left(1 \mathrm{H}, \mathrm{dtd}, J_{\mathrm{HF}}=25.1 \mathrm{~Hz}, J=\right.$ $\left.7.8 \mathrm{~Hz}, J_{\mathrm{HF}}=2.5 \mathrm{~Hz}\right), 7.29(2 \mathrm{H}, \mathrm{d}, J=8.5 \mathrm{~Hz}), 7.55(2 \mathrm{H}, \mathrm{d}, J=8.5 \mathrm{~Hz}) .{ }^{13} \mathrm{C} \mathrm{NMR}\left(126 \mathrm{MHz}, \mathrm{CDCl}_{3}\right): \delta$ 21.1, $30.6\left(\mathrm{~d}, J_{\mathrm{CF}}=4 \mathrm{~Hz}\right), 39.8\left(\mathrm{dd}, J_{\mathrm{CF}}=2,2 \mathrm{~Hz}\right), 76.0\left(\mathrm{dd}, J_{\mathrm{CF}}=23,21 \mathrm{~Hz}\right), 124.3\left(\mathrm{q}, J_{\mathrm{CF}}=272 \mathrm{~Hz}\right)$, $125.4\left(\mathrm{q}, J_{\mathrm{CF}}=4 \mathrm{~Hz}\right), 127.3,128.6\left(\mathrm{q}, J_{\mathrm{CF}}=32 \mathrm{~Hz}\right), 150.1,156.6\left(\mathrm{dd}, J_{\mathrm{CF}}=287,287 \mathrm{~Hz}\right) .{ }^{19} \mathrm{~F} \mathrm{NMR}(376$ $\left.\mathrm{MHz}, \mathrm{CDCl}_{3}\right): \delta 70.8\left(1 \mathrm{~F}, \mathrm{dd}, J_{\mathrm{FF}}=46 \mathrm{~Hz}, J_{\mathrm{FH}}=25 \mathrm{~Hz}\right), 73.2\left(1 \mathrm{~F}, \mathrm{br} \mathrm{d}, J_{\mathrm{FF}}=46 \mathrm{~Hz}\right), 98.7(3 \mathrm{~F}, \mathrm{~s})$. Anal. Calcd for $\mathrm{C}_{12} \mathrm{H}_{11} \mathrm{~F}_{5}$ : C, 57.60; H, 4.43. Found: C, 57.63; H, 4.58. 


\section{2-(2-Phenylethyl)-1,1-difluorohept-1-ene (1i)}

Butyllithium (0.63 mL, 1.67 $\mathrm{M}$ in hexane, $1.05 \mathrm{mmol})$ was added to a solution of $N, N, N^{\prime}, N^{\prime}$-tetramethylethylenediamine (TMEDA, $0.15 \quad \mathrm{~mL}, \quad 1.05 \quad \mathrm{mmol}$ ) and 4-phenyl-2-trifluoromethylbut-1-ene $(0.20 \mathrm{~g}, 1.0 \mathrm{mmol})$ in THF $(10 \mathrm{~mL})$ at $-78{ }^{\circ} \mathrm{C}$ under argon. After stirring for $1 \mathrm{~h}$ at the same temperature, the mixture was warmed to room temperature, and stirred for $1 \mathrm{~h}$. The reaction was quenched with aq. $\mathrm{NH}_{4} \mathrm{Cl}$, and organic materials were extracted with AcOEt three times. The combined extracts were washed with brine and dried over $\mathrm{Na}_{2} \mathrm{SO}_{4}$. After removal of the solvent under reduced pressure, the residue was purified by column chromatography on silica gel (hexane-AcOEt 100:1) to give $\mathbf{1 i}(0.17 \mathrm{~g}, 74 \%)$ as a colorless liquid. IR (neat): 2929, 2860, 1745, 1496, 1456, 1259, 1209, 1051, 739, $696 \mathrm{~cm}^{-1} .{ }^{1} \mathrm{H}$ NMR (400 MHz, $\left.\mathrm{CDCl}_{3}\right): \delta 0.89(3 \mathrm{H}, \mathrm{t}, J=7.1 \mathrm{~Hz})$, $1.21-1.35(4 \mathrm{H}, \mathrm{m}), 1.40(2 \mathrm{H}, \mathrm{tt}, J=7.5,7.5 \mathrm{~Hz}), 1.97\left(2 \mathrm{H}, \mathrm{tdd}, J=7.5 \mathrm{~Hz}, J_{\mathrm{HF}}=2.2,2.0 \mathrm{~Hz}\right), 2.26(2 \mathrm{H}$, $\left.\operatorname{tdd}, J=8.0 \mathrm{~Hz}, J_{\mathrm{HF}}=2.2,2.0 \mathrm{~Hz}\right), 2.69(2 \mathrm{H}, \mathrm{t}, J=8.0 \mathrm{~Hz}), 7.15-7.22(3 \mathrm{H}, \mathrm{m}), 7.28(2 \mathrm{H}, \mathrm{dd}, J=7.3,7.3$ Hz). ${ }^{13} \mathrm{C}$ NMR (126 MHz, $\left.\mathrm{CDCl}_{3}\right): \delta 14.0,22.4,25.9\left(\mathrm{~d}, J_{\mathrm{CF}}=2 \mathrm{~Hz}\right), 27.1,28.0\left(\mathrm{~d}, J_{\mathrm{CF}}=2 \mathrm{~Hz}\right), 31.3$, $34.0,88.4\left(\mathrm{dd}, J_{\mathrm{CF}}=17,17 \mathrm{~Hz}\right), 126.0,128.3,128.4,141.4,153.4\left(\mathrm{dd}, J_{\mathrm{CF}}=283,283 \mathrm{~Hz}\right) .{ }^{19} \mathrm{~F} \mathrm{NMR}$ $\left(376 \mathrm{MHz}, \mathrm{CDCl}_{3}\right): \delta 65.3\left(1 \mathrm{~F}, \mathrm{~d}, J_{\mathrm{FF}}=56 \mathrm{~Hz}\right), 65.7\left(1 \mathrm{~F}, \mathrm{~d}, J_{\mathrm{FF}}=56 \mathrm{~Hz}\right)$. Anal. Calcd for $\mathrm{C}_{15} \mathrm{H}_{20} \mathrm{~F}_{2}: \mathrm{C}$, 75.60; H, 8.46. Found: C, 75.66; H, 8.24.

\section{2-(2,2-Difluorovinyl)biphenyl (1j)}

Dibromodifluoromethane $(1.05 \mathrm{~mL}, 11.5 \mathrm{mmol})$ was added to a DMF $(8.0 \mathrm{~mL})$ solution of triphenylphosphine $(3.02 \mathrm{~g}, 11.5 \mathrm{mmol})$ at $0{ }^{\circ} \mathrm{C}$ under argon. The reaction mixture was stirred for $30 \mathrm{~min}$ at room temperature, and then biphenyl-2-carbaldehyde $(0.70 \mathrm{~g}, 3.84 \mathrm{mmol})$ and $\mathrm{Zn}$ powder $(0.83 \mathrm{~g}$, $11.5 \mathrm{mg}$ ) were added slowly at $0{ }^{\circ} \mathrm{C}$. After the mixture was stirred for $1 \mathrm{~h}$ at room temperature, aq. $\mathrm{NaHCO}_{3}$ was added to quench the reaction. Organic materials were extracted with pentane three times. The combined extracts were washed with brine and dried over $\mathrm{Na}_{2} \mathrm{SO}_{4}$. After removal of the solvent under reduced pressure, the residue was purified by column chromatography on silica gel (pentane) to give $\mathbf{1 j}(0.31 \mathrm{~g}, 37 \%)$ as a colorless liquid. IR (neat): 3060, 1722, 1479, 1348, 1232, 1171, 1072, 1009 , 935, $700 \mathrm{~cm}^{-1} .{ }^{1} \mathrm{H}$ NMR $\left(400 \mathrm{MHz}, \mathrm{CDCl}_{3}\right): \delta 5.21\left(1 \mathrm{H}, \mathrm{dd}, J_{\mathrm{HF}}=26.1,4.2 \mathrm{~Hz}\right), 7.28-7.44(8 \mathrm{H}, \mathrm{m})$, $7.59(1 \mathrm{H}, \mathrm{d}, J=7.7 \mathrm{~Hz}) .{ }^{13} \mathrm{C} \mathrm{NMR}\left(126 \mathrm{MHz}, \mathrm{CDCl}_{3}\right): \delta 80.6\left(\mathrm{dd}, J_{\mathrm{CF}}=30,13 \mathrm{~Hz}\right), 126.9,127.3,127.5$, $127.9\left(\mathrm{dd}, J_{\mathrm{CF}}=6,6 \mathrm{~Hz}\right), 128.1\left(\mathrm{~d}, J_{\mathrm{CF}}=9 \mathrm{~Hz}\right), 128.2,129.5,130.1,140.7,141.1\left(\mathrm{~d}, J_{\mathrm{CF}}=4 \mathrm{~Hz}\right), 156.2$ $\left(\mathrm{dd}, J_{\mathrm{CF}}=298,287 \mathrm{~Hz}\right) .{ }^{19} \mathrm{~F} \mathrm{NMR}\left(376 \mathrm{MHz}, \mathrm{CDCl}_{3}\right): \delta 76.3\left(\mathrm{dd}, J_{\mathrm{FF}}=31 \mathrm{~Hz}, J_{\mathrm{FH}}=4 \mathrm{~Hz}\right), 78.1(\mathrm{ddd}$, $J_{\mathrm{FF}}=31 \mathrm{~Hz}, J_{\mathrm{FH}}=26,3 \mathrm{~Hz}$ ). Anal. Calcd for $\mathrm{C}_{14} \mathrm{H}_{10} \mathrm{~F}_{2}: \mathrm{C}, 77.77 ; \mathrm{H}, 4.66$. Found: C, 77.70; H, 4.89.

\section{1,2-Dihydro-3H-phenanthren-4-one $(2 a)^{3}$ 3,4-Dihydro-2H-anthracen-1-one (3a) $)^{3}$}

\section{4-Fluorophenanthrene (4a)}

$\left[\mathrm{Pd}(\mathrm{MeCN})_{4}\right]\left(\mathrm{BF}_{4}\right)_{2} \quad(8.8 \mathrm{mg}, 0.02 \mathrm{mmol})$ in HFIP $(2.0 \mathrm{~mL})$ was added to a solution of 1,1-difluoro-4-(2-naphthyl)but-1-ene (1a, $87 \mathrm{mg}, 0.40 \mathrm{mmol})$ and $\mathrm{BF}_{3} \cdot \mathrm{OEt}_{2}(0.050 \mathrm{~mL}, 0.37 \mathrm{mmol})$ in HFIP $(2.0 \mathrm{~mL})$ at $0{ }^{\circ} \mathrm{C}$ under argon. After the mixture was stirred for $40 \mathrm{~min}$ at room temperature, phosphate buffer ( $\mathrm{pH}$ 7) was added to quench the reaction. Organic materials were extracted with $\mathrm{CH}_{2} \mathrm{Cl}_{2}$ three times. The combined extracts were washed with brine and dried over $\mathrm{Na}_{2} \mathrm{SO}_{4}$. After removal of the solvent under reduced pressure, the residue was purified by thin-layer chromatography on 
silica gel (hexane-AcOEt 10:1) to give $\mathbf{2 a}(67 \mathrm{mg}, 86 \%$ ) as a pale yellow liquid, along with $\mathbf{3 a}$ (2.3 $\mathrm{mg}$, $3 \%)$ as a colorless solid and $\mathbf{4 a}(3.9 \mathrm{mg}, 5 \%)$ as a colorless solid.

2a: IR (neat): 3456, 2945, 1676, 1448, 1348, 1176, 918, $750 \mathrm{~cm}^{-1} .{ }^{1} \mathrm{H}$ NMR (500 MHz, $\left.\mathrm{CDCl}_{3}\right): \delta 2.17$ $(2 \mathrm{H}, \mathrm{tt}, J=6.7,6.1 \mathrm{~Hz}), 2.77(2 \mathrm{H}, \mathrm{t}, J=6.7 \mathrm{~Hz}), 3.09(2 \mathrm{H}, \mathrm{t}, J=6.1 \mathrm{~Hz}), 7.29(1 \mathrm{H}, \mathrm{d}, J=8.2 \mathrm{~Hz}), 7.47$ $(1 \mathrm{H}, \mathrm{ddd}, J=8.2,8.2,0.9 \mathrm{~Hz}), 7.61(1 \mathrm{H}, \mathrm{ddd}, J=8.2,8.2,0.9 \mathrm{~Hz}), 7.77(1 \mathrm{H}, \mathrm{dd}, J=8.2,0.9 \mathrm{~Hz}), 7.89$ $(1 \mathrm{H}, \mathrm{d}, J=8.2 \mathrm{~Hz}), 9.41(1 \mathrm{H}, \mathrm{dd}, J=8.2,0.9 \mathrm{~Hz}) .{ }^{13} \mathrm{C} \mathrm{NMR}\left(126 \mathrm{MHz}, \mathrm{CDCl}_{3}\right): \delta 23.0,31.6,41.1$, 125.8, 126.6, 127.0, 127.2, 128.3, 128.8, 131.3, 132.7, 134.2, 146.8, 200.5. Anal. Calcd for $\mathrm{C}_{14} \mathrm{H}_{12} \mathrm{O}: \mathrm{C}$, 85.68; H, 6.16. Found: C, 85.42; H, 6.19.

3a: IR (neat): 2922, 2852, 1670, 1508, 1458, 1196, 1117, 814, $746 \mathrm{~cm}^{-1} .{ }^{1} \mathrm{H}$ NMR (500 MHz, $\left.\mathrm{CDCl}_{3}\right): \delta$ $2.17(2 \mathrm{H}, \mathrm{tt}, J=6.4,6.1 \mathrm{~Hz}), 2.74(2 \mathrm{H}, \mathrm{t}, J=6.4 \mathrm{~Hz}), 3.11(2 \mathrm{H}, \mathrm{t}, J=6.1 \mathrm{~Hz}), 7.44(1 \mathrm{H}, \mathrm{dd}, J=7.8,7.8$ $\mathrm{Hz}), 7.53(1 \mathrm{H}, \mathrm{dd}, J=7.8,7.8 \mathrm{~Hz}), 7.66(1 \mathrm{H}, \mathrm{s}), 7.76(1 \mathrm{H}, \mathrm{d}, J=7.8 \mathrm{~Hz}), 7.93(1 \mathrm{H}, \mathrm{d}, J=7.8 \mathrm{~Hz}), 8.60$ $(1 \mathrm{H}, \mathrm{s}) .{ }^{13} \mathrm{C}$ NMR $\left(126 \mathrm{MHz}, \mathrm{CDCl}_{3}\right): \delta 23.3,30.0,39.7,125.9,126.7,127.0,128.6,128.8,129.0,130.7$, 131.6, 135.8, 139.3, 198.9. HRMS (FAB): $\mathrm{m} / \mathrm{z}$ calcd for $\mathrm{C}_{14} \mathrm{H}_{13} \mathrm{O}\left([\mathrm{M}+\mathrm{H}]^{+}\right): 197.0967$; found: 197.0958 . 4a: IR (neat): 3055, 2925, 1572, 1439, 1232, 1203, 999, 737, $704 \mathrm{~cm}^{-1} .{ }^{1} \mathrm{H}$ NMR (500 MHz, $\left.\mathrm{CDCl}_{3}\right): \delta$ $7.36\left(1 \mathrm{H}, \mathrm{ddd}, J_{\mathrm{HF}}=14.2 \mathrm{~Hz}, J=8.1,1.5 \mathrm{~Hz}\right), 7.53\left(1 \mathrm{H}, \mathrm{ddd}, J=8.1,8.1 \mathrm{~Hz}, J_{\mathrm{HF}}=4.9 \mathrm{~Hz}\right), 7.69(1 \mathrm{H}$, $\mathrm{ddd}, J=8.1,8.1,1.5 \mathrm{~Hz}), 7.67-7.71(2 \mathrm{H}, \mathrm{m}), 7.73\left(1 \mathrm{H}, \mathrm{dd}, J=8.1 \mathrm{~Hz}, J_{\mathrm{HF}}=2.0 \mathrm{~Hz}\right), 7.77(1 \mathrm{H}, \mathrm{d}, J=$ $8.1 \mathrm{~Hz}), 7.91(1 \mathrm{H}, \mathrm{dd}, J=8.1,1.5 \mathrm{~Hz}), 9.12\left(1 \mathrm{H}, \mathrm{ddd}, J=8.1,1.5 \mathrm{~Hz}, J_{\mathrm{HF}}=0.4 \mathrm{~Hz}\right) .{ }^{13} \mathrm{C} \mathrm{NMR}(126$ $\left.\mathrm{MHz}, \mathrm{CDCl}_{3}\right): \delta 113.3\left(\mathrm{~d}, J_{\mathrm{CF}}=25 \mathrm{~Hz}\right), 119.5\left(\mathrm{~d}, J_{\mathrm{CF}}=9 \mathrm{~Hz}\right), 124.5\left(\mathrm{~d}, J_{\mathrm{CF}}=3 \mathrm{~Hz}\right), 126.4\left(\mathrm{~d}, J_{\mathrm{CF}}=3\right.$ $\mathrm{Hz}), 126.7\left(\mathrm{~d}, J_{\mathrm{CF}}=10 \mathrm{~Hz}\right), 126.8\left(\mathrm{~d}, J_{\mathrm{CF}}=1 \mathrm{~Hz}\right), 127.1\left(\mathrm{~d}, J_{\mathrm{CF}}=2 \mathrm{~Hz}\right), 127.7\left(\mathrm{~d}, J_{\mathrm{CF}}=25 \mathrm{~Hz}\right), 128.3$, $128.4\left(\mathrm{~d}, J_{\mathrm{CF}}=5 \mathrm{~Hz}\right), 128.4,132.5,134.8\left(\mathrm{~d}, J_{\mathrm{CF}}=4 \mathrm{~Hz}\right), 159.1\left(\mathrm{~d}, J_{\mathrm{CF}}=301 \mathrm{~Hz}\right) .{ }^{19} \mathrm{~F}$ NMR $(470 \mathrm{MHz}$, $\mathrm{CDCl}_{3}$ ): $\delta 51.6\left(\right.$ br d, $\left.J_{\mathrm{FH}}=14 \mathrm{~Hz}\right)$. HRMS (FAB): $m / z$ calcd for $\mathrm{C}_{14} \mathrm{H}_{10} \mathrm{~F}\left([\mathrm{M}+\mathrm{H}]^{+}\right): 197.0767$; found: 197.0758.

\section{3,4-Dihydro-2H-naphthalen-1-one $(2 \mathrm{~b})^{3}$}

Compound 2b was obtained by the method described for 2a. IR (neat): 3066, 2945, 1686, 1601, 1454, 1325, 1286, 1227, 1026, $764 \mathrm{~cm}^{-1} .{ }^{1} \mathrm{H}$ NMR $\left(500 \mathrm{MHz}, \mathrm{CDCl}_{3}\right): \delta 2.15(2 \mathrm{H}, \mathrm{tt}, J=6.3,6.3 \mathrm{~Hz}), 2.66$ $(2 \mathrm{H}, \mathrm{t}, J=6.3 \mathrm{~Hz}), 2.97(2 \mathrm{H}, \mathrm{t}, J=6.3 \mathrm{~Hz}), 7.25(1 \mathrm{H}, \mathrm{d}, J=7.6 \mathrm{~Hz}), 7.31(1 \mathrm{H}, \mathrm{dd}, J=7.6,7.6 \mathrm{~Hz}), 7.47$ $(1 \mathrm{H}, \mathrm{ddd}, J=7.6,7.6,1.1 \mathrm{~Hz}), 8.04(1 \mathrm{H}, \mathrm{dd}, J=7.6,1.1 \mathrm{~Hz}) .{ }^{13} \mathrm{C} \mathrm{NMR}\left(126 \mathrm{MHz}, \mathrm{CDCl}_{3}\right): \delta 23.3,29.7$, 39.2, 126.6, 127.2, 128.8, 132.6, 133.4, 144.5, 198.4. Anal. Calcd for $\mathrm{C}_{10} \mathrm{H}_{10} \mathrm{O}: \mathrm{C}, 82.16 ; \mathrm{H}, 6.89$. Found: C, 81.90; H, 7.06 .

\section{3,4-Dihydro-4-methyl-2H-naphthalen-1-one $(2 \mathrm{c})^{3}$}

Compound 2c was obtained by the method described for 2a. IR (neat): 2970, 1690, 1600, 1460, 1335, 1290, 1195, 1010, $770 \mathrm{~cm}^{-1} .{ }^{1} \mathrm{H} \mathrm{NMR}\left(500 \mathrm{MHz}, \mathrm{CDCl}_{3}\right): \delta 1.40(3 \mathrm{H}, \mathrm{d}, J=7.0 \mathrm{~Hz}), 1.85-1.95(1 \mathrm{H}, \mathrm{m})$, 2.20-2.28 (1H, m), 2.59 (1H, ddd, $J=17.4,8.6,4.5 \mathrm{~Hz}), 2.79$ (1H, ddd, $J=17.4,8.5,4.4 \mathrm{~Hz}), 3.05-3.13$ $(1 \mathrm{H}, \mathrm{m}), 7.30(1 \mathrm{H}, \mathrm{dd}, J=7.9,7.9 \mathrm{~Hz}), 7.32(1 \mathrm{H}, \mathrm{d}, J=7.9 \mathrm{~Hz}), 7.50(1 \mathrm{H}, \mathrm{ddd}, J=7.9,7.9,1.5 \mathrm{~Hz})$, $8.03(1 \mathrm{H}, \mathrm{dd}, J=7.9,1.5 \mathrm{~Hz}) .{ }^{13} \mathrm{C}$ NMR $\left(126 \mathrm{MHz}, \mathrm{CDCl}_{3}\right): \delta 20.7,30.5,32.8,36.3,126.5,127.2,127.4$, 131.8, 133.6, 148.9, 198.4. Anal. Calcd for $\mathrm{C}_{11} \mathrm{H}_{12} \mathrm{O}: \mathrm{C}, 82.46$; H, 7.55. Found: C, 82.31; H, 7.76.

\section{4,7-Dimethyl-3,4-dihydro-2H-naphthalen-1-one (2d) ${ }^{4}$}

Compound 2d was obtained by the method described for 2a. IR (neat): 2929, 1680, 1610, 1495, 1408, 
1327, 1281, 1180, 1018, $816 \mathrm{~cm}^{-1} .{ }^{1} \mathrm{H}$ NMR $\left(500 \mathrm{MHz}, \mathrm{CDCl}_{3}\right): \delta 1.38(3 \mathrm{H}, \mathrm{d}, J=6.9 \mathrm{~Hz}), 1.84-1.92$ $(1 \mathrm{H}, \mathrm{m}), 2.19-2.26(1 \mathrm{H}, \mathrm{m}), 2.36(3 \mathrm{H}, \mathrm{s}), 2.58(1 \mathrm{H}, \mathrm{ddd}, J=17.3,8.9,4.8 \mathrm{~Hz}), 2.78(1 \mathrm{H}, \mathrm{ddd}, J=17.3$, 8.5, $4.5 \mathrm{~Hz}), 3.01-3.09(1 \mathrm{H}, \mathrm{m}), 7.22(1 \mathrm{H}, \mathrm{d}, J=7.9 \mathrm{~Hz}), 7.32(1 \mathrm{H}, \mathrm{dd}, J=7.9,1.7 \mathrm{~Hz}), 7.84(1 \mathrm{H}, \mathrm{d}, J=$ $1.7 \mathrm{~Hz}) .{ }^{13} \mathrm{C}$ NMR (101 MHz, $\left.\mathrm{CDCl}_{3}\right): \delta 20.7,20.8,30.7,32.4,36.4,127.3,127.3,131.6,134.5,136.1$, 146.1, 198.7. Anal. Calcd for $\mathrm{C}_{12} \mathrm{H}_{14} \mathrm{O}: \mathrm{C}, 82.72 ; \mathrm{H}, 8.10$. Found: $\mathrm{C}, 82.69 ; \mathrm{H}, 8.20$.

\section{7-Methoxy-4-methyl-3,4-dihydro-2H-naphthalen-1-one (2e)}

Compound 2e was obtained by the method described for 2a. IR (neat): 2958, 2927, 1682, 1606, 1493, $1319,1277,1230,1036,822 \mathrm{~cm}^{-1} .{ }^{1} \mathrm{H}$ NMR (400 MHz, $\left.\mathrm{CDCl}_{3}\right): \delta 1.38(3 \mathrm{H}, \mathrm{d}, J=7.1 \mathrm{~Hz}), 1.82-1.92$ $(1 \mathrm{H}, \mathrm{m}), 2.18-2.27(1 \mathrm{H}, \mathrm{m}), 2.58(1 \mathrm{H}, \mathrm{ddd}, J=17.3,9.0,4.9 \mathrm{~Hz}), 2.78(1 \mathrm{H}, \mathrm{ddd}, J=17.3,8.3,4.4 \mathrm{~Hz})$, 2.98-3.07 (1H, m), $3.84(3 \mathrm{H}, \mathrm{s}), 7.08(1 \mathrm{H}, \mathrm{dd}, J=8.4,2.8 \mathrm{~Hz}), 7.24(1 \mathrm{H}, \mathrm{d}, J=8.4 \mathrm{~Hz}), 7.50(1 \mathrm{H}, \mathrm{d}, J=$ $2.8 \mathrm{~Hz}) .{ }^{13} \mathrm{C}$ NMR $\left(101 \mathrm{MHz}, \mathrm{CDCl}_{3}\right): \delta 20.9,30.9,32.2,36.4,55.5,109.1,121.8,128.6,132.6,141.5$, 158.0, 198.2. HRMS (FAB): $\mathrm{m} / z$ calcd for $\mathrm{C}_{12} \mathrm{H}_{15} \mathrm{O}_{2}\left([\mathrm{M}+\mathrm{H}]^{+}\right)$: 191.1072 ; found: 191.1058.

\section{6-Methoxy-4-methyl-3,4-dihydro-2H-naphthalen-1-one (2f)}

Compound 2f was obtained by the method described for 2a. IR (neat): 2935, 1672, 1593, 1489, 1458, 1331, 1265, 1128, 1009, $820 \mathrm{~cm}^{-1} .{ }^{1} \mathrm{H}$ NMR (400 MHz, $\left.\mathrm{CDCl}_{3}\right): \delta 1.39(3 \mathrm{H}, \mathrm{d}, J=7.1 \mathrm{~Hz}), 1.83-1.94$ $(1 \mathrm{H}, \mathrm{m}), 2.17-2.27(1 \mathrm{H}, \mathrm{m}), 2.55(1 \mathrm{H}$, ddd, $J=17.4,8.3,4.6 \mathrm{~Hz}), 2.74(1 \mathrm{H}, \mathrm{ddd}, J=17.4,8.6,4.6 \mathrm{~Hz})$, 2.99-3.09 (1H, m), $3.86(3 \mathrm{H}, \mathrm{s}), 6.77(1 \mathrm{H}, \mathrm{d}, J=2.5 \mathrm{~Hz}), 6.82(1 \mathrm{H}, \mathrm{dd}, J=8.7,2.5 \mathrm{~Hz}), 8.01(1 \mathrm{H}, \mathrm{d}, J=$ $8.7 \mathrm{~Hz}) .{ }^{13} \mathrm{C}$ NMR $\left(101 \mathrm{MHz}, \mathrm{CDCl}_{3}\right): \delta 20.6,30.7,33.2,36.1,55.4,111.8,112.3,125.5,129.7,151.3$, 163.6, 197.0. HRMS (FAB): $m / z$ calcd for $\mathrm{C}_{12} \mathrm{H}_{15} \mathrm{O}_{2}\left([\mathrm{M}+\mathrm{H}]^{+}\right)$: 191.1072; found: 191.1062 .

\section{7-Hydroxy-4-methyl-3,4-dihydro-2H-naphthalen-1-one (2g)}

Compound $\mathbf{2 g}$ was obtained by the method described for 2a. IR (neat): 3213, 1647, 1616, 1570, 1498, $1458,1356,1294,889,820 \mathrm{~cm}^{-1} .{ }^{1} \mathrm{H}$ NMR $\left(500 \mathrm{MHz}, \mathrm{CDCl}_{3}\right): \delta 1.37(3 \mathrm{H}, \mathrm{d}, J=7.0 \mathrm{~Hz}), 1.83-1.92$ $(1 \mathrm{H}, \mathrm{m}), 2.18-2.27(1 \mathrm{H}, \mathrm{m}), 2.60(1 \mathrm{H}, \mathrm{ddd}, J=17.5,9.1,4.7 \mathrm{~Hz}), 2.80(1 \mathrm{H}, \mathrm{ddd}, J=17.5,8.3,4.5 \mathrm{~Hz})$, 2.99-3.08 (1H, m), $6.52(1 \mathrm{H}, \mathrm{s}), 7.10(1 \mathrm{H}, \mathrm{dd}, J=8.4,2.7 \mathrm{~Hz}), 7.24(1 \mathrm{H}, \mathrm{d}, J=8.4 \mathrm{~Hz}), 7.64(1 \mathrm{H}, \mathrm{d}, J=$ $2.7 \mathrm{~Hz}) .{ }^{13} \mathrm{C} \mathrm{NMR}\left(126 \mathrm{MHz}, \mathrm{CDCl}_{3}\right): \delta 20.7,30.8,32.1,36.5,112.7,121.9,128.9,132.6,141.5,154.6$, 199.5. HRMS (FAB): $\mathrm{m} / z$ calcd for $\mathrm{C}_{11} \mathrm{H}_{13} \mathrm{O}_{2}\left([\mathrm{M}+\mathrm{H}]^{+}\right)$: 177.0916; found: 177.0922 .

\section{4-Methyl-7-trifluoromethyl-3,4-dihydro-2H-naphthalen-1-one (2h)}

Compound $\mathbf{2 h}$ was obtained by the method described for 2a. IR (neat): 2924, 2854, 1691, 1618, 1327 , $1259,1169,1122,1072,841 \mathrm{~cm}^{-1} .{ }^{1} \mathrm{H}$ NMR $\left(500 \mathrm{MHz}, \mathrm{CDCl}_{3}\right): \delta 1.44(3 \mathrm{H}, \mathrm{d}, J=7.1 \mathrm{~Hz}), 1.91-1.99$ $(1 \mathrm{H}, \mathrm{m}), 2.25-2.35(1 \mathrm{H}, \mathrm{m}), 2.66(1 \mathrm{H}, \mathrm{ddd}, J=17.5,8.6,4.8 \mathrm{~Hz}), 2.84(1 \mathrm{H}, \mathrm{ddd}, J=17.5,8.9,4.6 \mathrm{~Hz})$, $3.12-3.20(1 \mathrm{H}, \mathrm{m}), 7.48(1 \mathrm{H}, \mathrm{d}, J=8.1 \mathrm{~Hz}), 7.74(1 \mathrm{H}, \mathrm{dd}, J=8.1,1.9 \mathrm{~Hz}), 8.31(1 \mathrm{H}, \mathrm{d}, J=1.9 \mathrm{~Hz}) .{ }^{13} \mathrm{C}$ NMR (126 MHz, $\left.\mathrm{CDCl}_{3}\right): \delta 20.6,30.0,32.8,36.0,123.8\left(\mathrm{q}, J_{\mathrm{CF}}=273 \mathrm{~Hz}\right), 124.5\left(\mathrm{q}, J_{\mathrm{CF}}=4 \mathrm{~Hz}\right), 128.3$, $129.2\left(\mathrm{q}, J_{\mathrm{CF}}=33 \mathrm{~Hz}\right), 129.7\left(\mathrm{q}, J_{\mathrm{CF}}=3 \mathrm{~Hz}\right), 132.0,152.3,197.1 .{ }^{19} \mathrm{~F} \mathrm{NMR}\left(376 \mathrm{MHz}, \mathrm{CDCl}_{3}\right): \delta 98.9$ (s). HRMS (FAB): $m / z$ calcd for $\mathrm{C}_{12} \mathrm{H}_{12} \mathrm{~F}_{3} \mathrm{O}\left([\mathrm{M}+\mathrm{H}]^{+}\right)$: 229.0840; found: 229.0846.

\section{2-Pentyl-3,4-dihydro-2H-naphthalen-1-one (2i)}

Compound $\mathbf{2 i}$ was obtained by the method described for 2a. IR (neat): 2925, 2858, 1682, 1601, 1456, 
1288, 1225, 1028, 912, $741 \mathrm{~cm}^{-1} .{ }^{1} \mathrm{H}$ NMR $\left(400 \mathrm{MHz}, \mathrm{CDCl}_{3}\right): \delta 0.91(3 \mathrm{H}, \mathrm{t}, J=8.5 \mathrm{~Hz}), 1.25-1.51(7 \mathrm{H}$, $\mathrm{m}), 1.77-2.00(2 \mathrm{H}, \mathrm{m}), 2.24-2.26(1 \mathrm{H}, \mathrm{m}), 2.28-2.50(1 \mathrm{H}, \mathrm{m}), 2.78-3.01(2 \mathrm{H}, \mathrm{m}), 7.22(1 \mathrm{H}, \mathrm{d}, J=7.6$ $\mathrm{Hz}), 7.29(1 \mathrm{H}, \mathrm{dd}, J=7.6,7.6 \mathrm{~Hz}), 7.44(1 \mathrm{H}, \mathrm{ddd}, J=7.6,7.6,1.3 \mathrm{~Hz}), 8.02(1 \mathrm{H}, \mathrm{dd}, J=7.6,1.3 \mathrm{~Hz})$.

${ }^{13} \mathrm{C} \mathrm{NMR}\left(101 \mathrm{MHz}, \mathrm{CDCl}_{3}\right): \delta 14.1,22.6,26.8,28.2,28.3,29.4,32.0,47.5,126.4,127.4,128.6,132.5$, 132.9, 143.9, 200.3. Anal. Calcd for $\mathrm{C}_{15} \mathrm{H}_{20} \mathrm{O}$ : C, 83.28; H, 9.32. Found: C, 83.10; H, 9.36.

\section{9-Fluorophenanthrene (5j)}

Compound $\mathbf{5 j}$ was obtained by the method described for 2a. IR (neat): 3060, 1639, 1604, 1500, 1452, 1400, 1313, 1228, 1063, $872 \mathrm{~cm}^{-1} .{ }^{1} \mathrm{H}$ NMR $\left(400 \mathrm{MHz}, \mathrm{CDCl}_{3}\right): \delta 7.37\left(1 \mathrm{H}, \mathrm{d}, J_{\mathrm{HF}}=11.5 \mathrm{~Hz}\right)$, 7.55-7.63 (2H, m), $7.66(1 \mathrm{H}, \mathrm{ddd}, J=8.0,8.0,1.5 \mathrm{~Hz}), 7.71(1 \mathrm{H}, \mathrm{ddd}, J=8.0,8.0,1.5 \mathrm{~Hz}), 7.79-7.83$ $(1 \mathrm{H}, \mathrm{m}), 8.18(1 \mathrm{H}, \mathrm{dd}, J=8.0,1.5 \mathrm{~Hz}), 8.60-8.65(1 \mathrm{H}, \mathrm{m}), 8.67(1 \mathrm{H}, \mathrm{d}, J=8.0 \mathrm{~Hz}) .{ }^{13} \mathrm{C}$ NMR $(126$ $\left.\mathrm{MHz}, \mathrm{CDCl}_{3}\right): \delta 107.9\left(\mathrm{~d}, J_{\mathrm{CF}}=20 \mathrm{~Hz}\right), 121.3\left(\mathrm{~d}, J_{\mathrm{CF}}=6 \mathrm{~Hz}\right), 122.7,122.8,124.2\left(\mathrm{~d}, J_{\mathrm{CF}}=19 \mathrm{~Hz}\right)$, $125.8\left(\mathrm{~d}, J_{\mathrm{CF}}=2 \mathrm{~Hz}\right), 126.9,127.2,127.6,127.8,128.0\left(\mathrm{~d}, J_{\mathrm{CF}}=6 \mathrm{~Hz}\right), 131.8\left(\mathrm{~d}, J_{\mathrm{CF}}=6 \mathrm{~Hz}\right), 131.8(\mathrm{~d}$, $\left.J_{\mathrm{CF}}=10 \mathrm{~Hz}\right), 157.1\left(\mathrm{~d}, J_{\mathrm{CF}}=251 \mathrm{~Hz}\right) .{ }^{19} \mathrm{~F} \mathrm{NMR}\left(376 \mathrm{MHz}, \mathrm{CDCl}_{3}\right): \delta 36.2\left(\mathrm{~d}, J_{\mathrm{FH}}=12 \mathrm{~Hz}\right) . \mathrm{HRMS}$ (FAB): $m / z$ calcd for $\mathrm{C}_{14} \mathrm{H}_{10} \mathrm{~F}\left([\mathrm{M}+\mathrm{H}]^{+}\right)$: 197.0766; found: 197.0759 .

\section{4-(2-Bromophenyl)-1,1-difluorobut-1-ene (6a)}

To a mixture of dibromodifluoromethane $\left(\mathrm{CF}_{2} \mathrm{Br}_{2}, 1.28 \mathrm{~mL}, 13.1 \mathrm{mmol}\right)$ and microwave-dried molecular sieves $(4 \AA)$ powder $(1.7 \mathrm{~g})$ in THF $(15 \mathrm{~mL})$ was added tris(dimethylamino)phosphine $\left(\mathrm{P}\left(\mathrm{NMe}_{2}\right)_{3}\right.$, $5.1 \mathrm{~mL}, 26.3 \mathrm{mmol})$ at $-78{ }^{\circ} \mathrm{C}$. The mixture was stirred for $30 \mathrm{~min}$ at that temperature, and then warmed to room temperature. 3-(2-Bromophenyl)propanal ${ }^{5}(1.40 \mathrm{~g}, 6.57 \mathrm{mmol})$ was added, and the mixture was stirred for $10 \mathrm{~h}$. The reaction was quenched with phosphate buffer $(\mathrm{pH} 7)$, and organic materials were extracted with $\mathrm{Et}_{2} \mathrm{O}$ three times. The combined extracts were washed with brine and dried over $\mathrm{MgSO}_{4}$. After removal of the solvent under reduced pressure, the residue was purified by column chromatography on silica gel (AcOEt-hexane 1:50) to give 6a $(1.06 \mathrm{~g}, 65 \%)$ as a colorless liquid. IR (neat): 3066, 2935, 2870, 1747, 1471, 1221, 1026, $750 \mathrm{~cm}^{-1} .{ }^{1} \mathrm{H}$ NMR $\left(500 \mathrm{MHz}, \mathrm{CDCl}_{3}\right): \delta 2.31(2 \mathrm{H}$, tddd, $\left.J=7.9,7.7 \mathrm{~Hz}, J_{\mathrm{HF}}=1.8,1.8 \mathrm{~Hz}\right), 2.81(2 \mathrm{H}, \mathrm{t}, J=7.7 \mathrm{~Hz}), 4.19\left(1 \mathrm{H}, \mathrm{dtd}, J_{\mathrm{HF}}=25.3 \mathrm{~Hz}, J=7.9\right.$ $\left.\mathrm{Hz}, J_{\mathrm{HF}}=4.3 \mathrm{~Hz}\right), 7.08(1 \mathrm{H}, \mathrm{ddd}, J=7.7,7.7,1.5 \mathrm{~Hz}), 7.20(1 \mathrm{H}, \mathrm{dd}, J=7.7,1.5 \mathrm{~Hz}), 7.23(1 \mathrm{H}, \mathrm{ddd}, J=$ 7.7, 7.7, $1.5 \mathrm{~Hz}), 7.53(1 \mathrm{H}, \mathrm{dd}, J=7.7,1.5 \mathrm{~Hz}) .{ }^{13} \mathrm{C} \mathrm{NMR}\left(126 \mathrm{MHz}, \mathrm{CDCl}_{3}\right): \delta 22.5\left(\mathrm{~d}, J_{\mathrm{CF}}=4 \mathrm{~Hz}\right)$, $35.9\left(\mathrm{dd}, J_{\mathrm{CF}}=2,2 \mathrm{~Hz}\right), 77.0\left(\mathrm{dd}, J_{\mathrm{CF}}=23,21 \mathrm{~Hz}\right), 124.4,127.4,127.9,130.4,132.9,140.1,156.4(\mathrm{dd}$, $\left.J_{\mathrm{CF}}=288,285 \mathrm{~Hz}\right) .{ }^{19} \mathrm{~F} \mathrm{NMR}\left(470 \mathrm{MHz}, \mathrm{CDCl}_{3}\right): \delta 70.9\left(1 \mathrm{~F}, \mathrm{dd}, J_{\mathrm{FF}}=46 \mathrm{~Hz}, J_{\mathrm{FH}}=25 \mathrm{~Hz}\right), 73.1(1 \mathrm{~F}, \mathrm{~d}$, $J_{\mathrm{FF}}=46 \mathrm{~Hz}$ ). Anal. Calcd for $\mathrm{C}_{10} \mathrm{H}_{9} \mathrm{BrF}_{2}: \mathrm{C}, 48.61 ; \mathrm{H}, 3.67$. Found: $\mathrm{C}, 48.81 ; \mathrm{H}, 3.83$.

\section{2-(4,4-Difluorobut-3-ene-1-yl)phenyl trifluoromethanesulfonate (6b)}

Compound $\mathbf{6 b}$ was prepared by the method described for 6a. IR (neat): 2941, 2877, 1745, 1419, 1207, 1136, 887, $765 \mathrm{~cm}^{-1} .{ }^{1} \mathrm{H}$ NMR (500 MHz, $\left.\mathrm{CDCl}_{3}\right): \delta 2.33\left(2 \mathrm{H}\right.$, tddd, $\left.J=7.9,7.6 \mathrm{~Hz}, J_{\mathrm{HF}}=1.7,1.7 \mathrm{~Hz}\right)$, $2.80(2 \mathrm{H}, \mathrm{t}, J=7.6 \mathrm{~Hz}), 4.16\left(1 \mathrm{H}, \mathrm{dtd}, J_{\mathrm{HF}}=25.1 \mathrm{~Hz}, J=7.9 \mathrm{~Hz}, J_{\mathrm{HF}}=2.3 \mathrm{~Hz}\right), 7.24-7.34(4 \mathrm{H}, \mathrm{m}) .{ }^{13} \mathrm{C}$ NMR (126 MHz, $\left.\mathrm{CDCl}_{3}\right): \delta 22.6\left(\mathrm{~d}, J_{\mathrm{CF}}=5 \mathrm{~Hz}\right), 29.8\left(\mathrm{dd}, J_{\mathrm{CF}}=2,2 \mathrm{~Hz}\right), 76.7\left(\mathrm{dd}, J_{\mathrm{CF}}=23,21 \mathrm{~Hz}\right)$, $118.6\left(\mathrm{q}, J_{\mathrm{CF}}=320 \mathrm{~Hz}\right), 121.4,128.3,128.4,131.2,133.5,148.0,156.6\left(\mathrm{dd}, J_{\mathrm{CF}}=288,287 \mathrm{~Hz}\right) .{ }^{19} \mathrm{~F}$ NMR (470 MHz, $\left.\mathrm{CDCl}_{3}\right): \delta 71.3\left(1 \mathrm{~F}, \mathrm{dd}, J_{\mathrm{FF}}=45 \mathrm{~Hz}, J_{\mathrm{FH}}=25 \mathrm{~Hz}\right), 73.6\left(1 \mathrm{~F}, \mathrm{~d}, J_{\mathrm{FF}}=45 \mathrm{~Hz}\right), 87.8(3 \mathrm{~F}$, s). Anal. Calcd for $\mathrm{C}_{11} \mathrm{H}_{9} \mathrm{~F}_{5} \mathrm{O}_{3} \mathrm{~S}: \mathrm{C}, 41.78 ; \mathrm{H}, 2.87$. Found: $\mathrm{C}, 41.62 ; \mathrm{H}, 3.06$. 


\section{1-Fluoronaphthalene (7) \\ 1-Difluoromethyleneindane (8)}

Aryl bromide 6a (98.2 mg, $0.40 \mathrm{mmol}), \mathrm{Pd}\left(\mathrm{PPh}_{3}\right)_{4}(460 \mathrm{mg}, 0.40 \mathrm{mmol})$, and $\mathrm{PPh}_{3}(104 \mathrm{mg}, 0.40 \mathrm{mmol})$ were dissolved in DMA $(20 \mathrm{ml})$ and heated to $110^{\circ} \mathrm{C}$ for $7 \mathrm{~h}$ under argon. After the mixture was cooled to room temperature, the reaction was quenched with phosphate buffer ( $\mathrm{pH} 7$ ). The organic materials were extracted with AcOEt three times. The combined extracts were washed with brine and dried over $\mathrm{Na}_{2} \mathrm{SO}_{4}$. After removal of the solvent under reduced pressure, the residue was purified by thin-layer chromatography on silica gel (hexane) to give 7 (30.4 mg, 52\%) as a yellow liquid and 8 (19.3 mg, 29\%) as a colorless liquid.

7: IR (neat): $3064,1600,1390,1261,1228,1074,791,762 \mathrm{~cm}^{-1} .{ }^{1} \mathrm{H}$ NMR $\left(500 \mathrm{MHz}, \mathrm{CDCl}_{3}\right): \delta 7.12$ $\left(1 \mathrm{H}, \mathrm{dd}, J_{\mathrm{HF}}=10.6 \mathrm{~Hz}, J=7.9 \mathrm{~Hz}\right), 7.37\left(1 \mathrm{H}, \mathrm{ddd}, J=7.9,7.9 \mathrm{~Hz}, J_{\mathrm{HF}}=5.4 \mathrm{~Hz},\right), 7.47-7.55(2 \mathrm{H}, \mathrm{m})$, $7.60(1 \mathrm{H}, \mathrm{d}, J=7.9 \mathrm{~Hz}), 7.81-7.86(1 \mathrm{H}, \mathrm{m}), 8.02-8.13(1 \mathrm{H}, \mathrm{m}) .{ }^{13} \mathrm{C} \mathrm{NMR}\left(126 \mathrm{MHz}, \mathrm{CDCl}_{3}\right): \delta 104.4$ $\left(\mathrm{d}, J_{\mathrm{CF}}=20 \mathrm{~Hz}\right), 120.5\left(\mathrm{~d}, J_{\mathrm{CF}}=5 \mathrm{~Hz}\right), 123.6\left(\mathrm{~d}, J_{\mathrm{CF}}=4 \mathrm{~Hz}\right), 123.7\left(\mathrm{~d}, J_{\mathrm{CF}}=17 \mathrm{~Hz}\right), 125.6\left(\mathrm{~d}, J_{\mathrm{CF}}=8\right.$ $\mathrm{Hz}), 126.2\left(\mathrm{~d}, J_{\mathrm{CF}}=2 \mathrm{~Hz}\right), 126.8,127.5\left(\mathrm{~d}, J_{\mathrm{CF}}=3 \mathrm{~Hz}\right), 134.9\left(\mathrm{~d}, J_{\mathrm{CF}}=5 \mathrm{~Hz}\right), 158.8\left(\mathrm{~d}, J_{\mathrm{CF}}=252 \mathrm{~Hz}\right)$. ${ }^{19} \mathrm{~F}$ NMR (470 MHz, $\left.\mathrm{CDCl}_{3}\right): \delta 38.3-38.5(\mathrm{~m})$. Anal. Calcd for $\mathrm{C}_{10} \mathrm{H}_{7} \mathrm{~F}: \mathrm{C}, 82.17 ; \mathrm{H}, 4.83$. Found: C, 82.32; H, 5.12 .

8: IR (neat): $3072,2935,1735,1462,1236,1109,982,756 \mathrm{~cm}^{-1} .{ }^{1} \mathrm{H}$ NMR $\left(500 \mathrm{MHz}, \mathrm{CDCl}_{3}\right): \delta$ $2.74-2.79(2 \mathrm{H}, \mathrm{m}), 3.04(2 \mathrm{H}, \mathrm{t}, J=7.1 \mathrm{~Hz}), 7.14-7.24(3 \mathrm{H}, \mathrm{m}), 7.43(1 \mathrm{H}, \mathrm{d}, J=7.3 \mathrm{~Hz}) .{ }^{13} \mathrm{C}$ NMR $(126$ $\left.\mathrm{MHz}, \mathrm{CDCl}_{3}\right): \delta 24.3\left(\mathrm{dd}, J_{\mathrm{CF}}=2,2 \mathrm{~Hz}\right), 30.4,95.0\left(\mathrm{dd}, J_{\mathrm{CF}}=26,16 \mathrm{~Hz}\right), 123.2\left(\mathrm{dd}, J_{\mathrm{CF}}=9,2 \mathrm{~Hz}\right)$, 124.8, 126.9, $127.3\left(\mathrm{dd}, J_{\mathrm{CF}}=3,2 \mathrm{~Hz}\right), 136.0\left(\mathrm{dd}, J_{\mathrm{CF}}=5,4 \mathrm{~Hz}\right), 144.8\left(\mathrm{dd}, J_{\mathrm{CF}}=6,1 \mathrm{~Hz}\right), 151.7(\mathrm{dd}$, $\left.J_{\mathrm{CF}}=291,286 \mathrm{~Hz}\right) \cdot{ }^{19} \mathrm{~F} \mathrm{NMR}\left(470 \mathrm{MHz}, \mathrm{CDCl}_{3}\right): \delta 73.1\left(1 \mathrm{~F}, \mathrm{~d}, J_{\mathrm{FF}}=50 \mathrm{~Hz}\right), 73.4\left(1 \mathrm{~F}, \mathrm{ddd}, J_{\mathrm{FF}}=50 \mathrm{~Hz}\right.$, $J_{\mathrm{FH}}=3,3 \mathrm{~Hz}$ ). Anal. Calcd for $\mathrm{C}_{10} \mathrm{H}_{8} \mathrm{~F}_{2}: \mathrm{C}, 72.28 ; \mathrm{H}, 4.85$. Found: C, 71.90; H, 5.02.

\section{1,1-Dichloro-4-phenylbut-1-ene (9a) ${ }^{3}$}

To a solution of trichloroacetic acid $(9.31 \mathrm{~g}, 57.0 \mathrm{mmol})$ and 3-phenylpropanal $(5.00 \mathrm{~mL}, 38.0 \mathrm{mmol})$ in DMF $(55.0 \mathrm{~mL})$ was added sodium trichloroacetate $(10.6 \mathrm{~g}, 57.0 \mathrm{mmol})$ in portions at room temperature under argon. After addition was completed, the mixture was stirred at room temperature for $4 \mathrm{~h}$. The solution was cooled to $0{ }^{\circ} \mathrm{C}$, and acetic anhydride $(7.17 \mathrm{~mL}, 76.0 \mathrm{mmol})$ was added. The mixture was allowed to warm to room temperature and stirred for an additional $4 \mathrm{~h}$. After the reaction mixture was diluted with acetic acid $(50.0 \mathrm{~mL})$ and cooled to $0{ }^{\circ} \mathrm{C}$, zinc powder $(5.52 \mathrm{~g}, 76.0 \mathrm{mmol})$ was added. The solution was stirred for $1 \mathrm{~h}$ at $60{ }^{\circ} \mathrm{C}$ and then cooled to room temperature. To the solution was added water, and then organic materials were extracted with hexane three times. The combined extracts were washed with water and brine, and dried over $\mathrm{Na}_{2} \mathrm{SO}_{4}$. After removal of the solvent under reduced pressure, the residue was purified by column chromatography on silica gel (hexane) to give 9a (6.29 $\mathrm{g}$, $82 \%$ ) as a colorless liquid. IR (neat): $3028,2858,1620,1496,1454,1084,1030,877,746,698 \mathrm{~cm}^{-1} .{ }^{1} \mathrm{H}$ NMR (400 MHz, $\left.\mathrm{CDCl}_{3}\right): \delta 2.49(2 \mathrm{H}, \mathrm{td}, J=7.7,7.3 \mathrm{~Hz}), 2.72(2 \mathrm{H}, \mathrm{t}, J=7.7 \mathrm{~Hz}), 5.87(1 \mathrm{H}, \mathrm{t}, J=7.3$ $\mathrm{Hz}), 7.16-7.23(3 \mathrm{H}, \mathrm{m}), 7.30(2 \mathrm{H}, \mathrm{dd}, J=7.3,7.3 \mathrm{~Hz}) .{ }^{13} \mathrm{C} \mathrm{NMR}\left(101 \mathrm{MHz}, \mathrm{CDCl}_{3}\right): \delta 31.3,34.3,120.5$, 126.2, 128.3, 128.4, 128.8, 140.5. Anal. Calcd for $\mathrm{C}_{10} \mathrm{H}_{10} \mathrm{Cl}_{2}$ : C, 59.73; H, 5.01. Found: C, 59.72; H, 5.09 . 


\section{1,1-Dibromo-4-phenylbut-1-ene $(9 b)^{3,6}$}

To a solution of triphenylphosphine $(15.6 \mathrm{~g}, 59.6 \mathrm{mmol})$ in toluene $(70.0 \mathrm{~mL})$ was added tetrabromomethane $(9.88 \mathrm{~g}, 29.8 \mathrm{mmol})$ at room temperature under argon. After the reaction mixture was stirred for $0.5 \mathrm{~h}$ at room temperature, 3-phenylpropanal $(1.96 \mathrm{~mL}, 14.9 \mathrm{mmol})$ was added at room temperature. The mixture was heated at reflux for $2 \mathrm{~h}$, and phosphate buffer $(\mathrm{pH} 7)$ was added to quench the reaction. Organic materials were extracted with AcOEt three times. The combined extracts were washed with brine and dried over $\mathrm{Na}_{2} \mathrm{SO}_{4}$. After removal of the solvent under reduced pressure, the residue was purified by column chromatography on silica gel (hexane) to give $\mathbf{9 b}(3.07 \mathrm{~g}, 71 \%)$ as a colorless liquid. IR(neat): 3026, 2856, 1558, 1541, 1496, 1454, 1338, 1082, 748, $698 \mathrm{~cm}^{-1}$. ${ }^{1} \mathrm{H}$ NMR $\left(400 \mathrm{MHz}, \mathrm{CDCl}_{3}\right): \delta 2.42(2 \mathrm{H}, \mathrm{td}, J=7.7,7.1 \mathrm{~Hz}), 2.73(2 \mathrm{H}, \mathrm{t}, J=7.7 \mathrm{~Hz}), 6.41(1 \mathrm{H}, \mathrm{t}, J=7.1 \mathrm{~Hz})$, 7.16-7.24 (3H, m), $7.30(2 \mathrm{H}, \mathrm{dd}, J=7.3,7.3 \mathrm{~Hz}) .{ }^{13} \mathrm{C} \mathrm{NMR}\left(101 \mathrm{MHz}, \mathrm{CDCl}_{3}\right): \delta 33.9,34.7,89.4$, 126.2, 128.3, 128.4, 137.5, 140.4. Anal. Calcd for $\mathrm{C}_{10} \mathrm{H}_{10} \mathrm{Br}_{2}$ : C, 41.42; H, 3.48. Found: C, 41.43; H, 3.49 .

\section{Referances}

(1) Ichikawa, J. J. Fluorine. Chem. 2000, 105, 257-263.

(2) Bégué, J. P.; Bonnet-Delpon, D.; Rock, M. H. J. Chem. Soc., Perkin Trans. 1 1996, 1409-1413.

(3) Ichikawa, J.; Jyono, H.; Kudo, T.; Fujiwara, M.; Yokota, M. Synthesis 2005, 39-46.

(4) Davies, H. M. L.; Walji, A. M. Angew. Chem. Int. Ed. 2005, 44, 1733-1735.

(5) Wolfe, J. P.; Rennels, R. A.; Buchwald, S. L. Tetrahedron 1996, 52, 7525-7546.

(6) Wang, Z.; Campagna, S.; Xu, G.; Pierce, M. E.; Fortunak, J. M.; Confalone, P. N. Tetrahedron Lett. 2005, 41, 4007-4009 


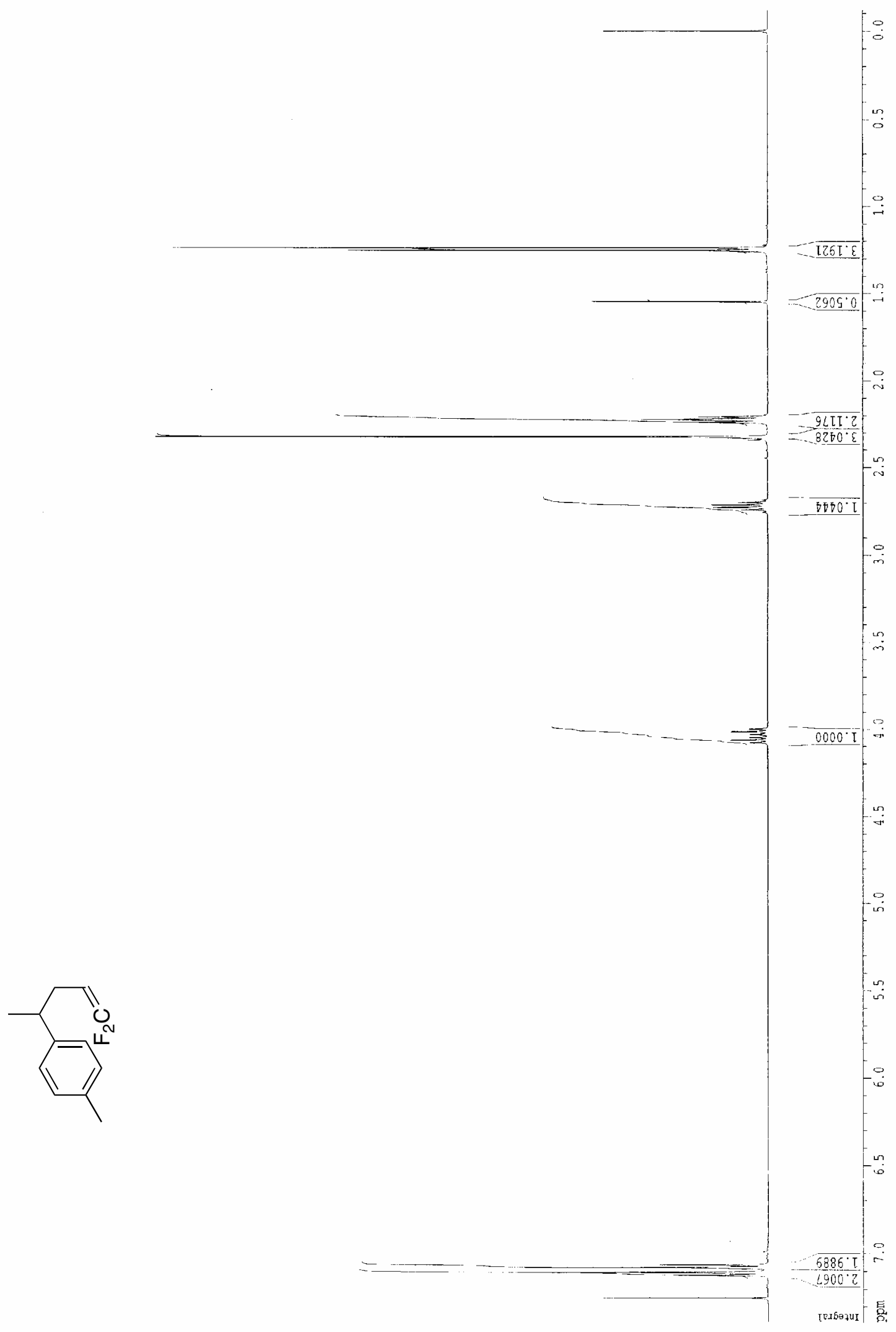

S-10 


$$
\mid
$$




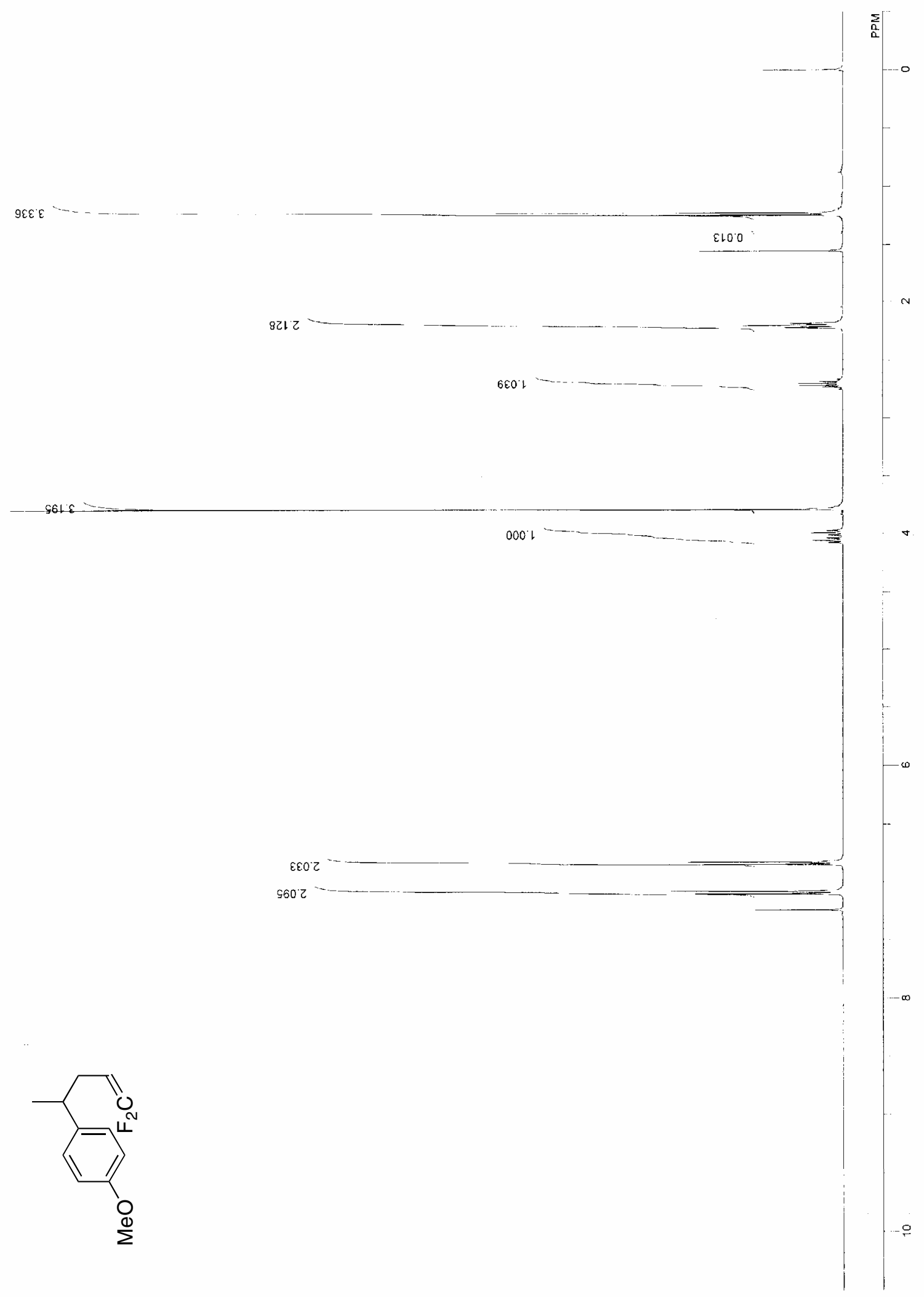

S-12 


$$
\mid
$$




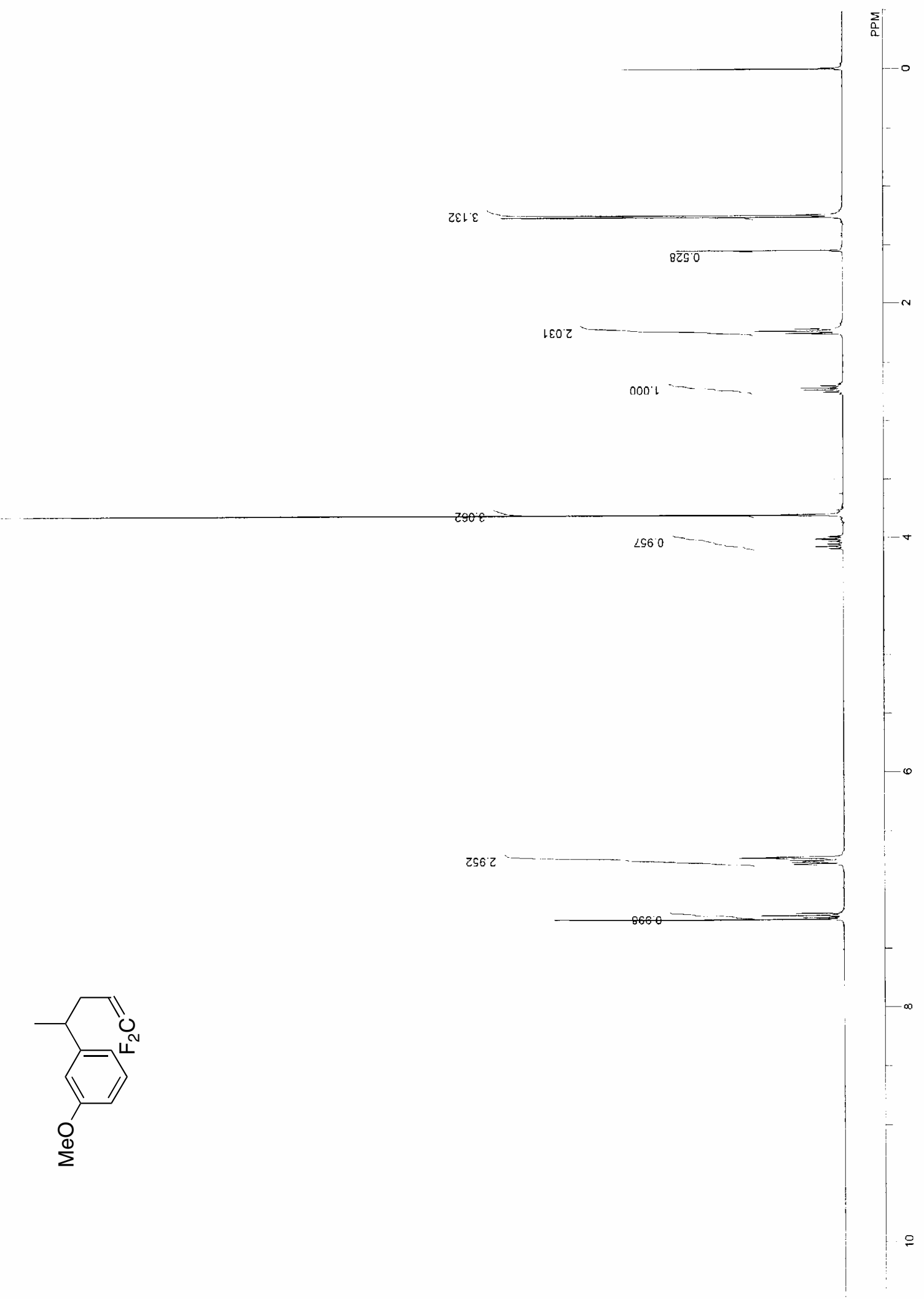

S-14 


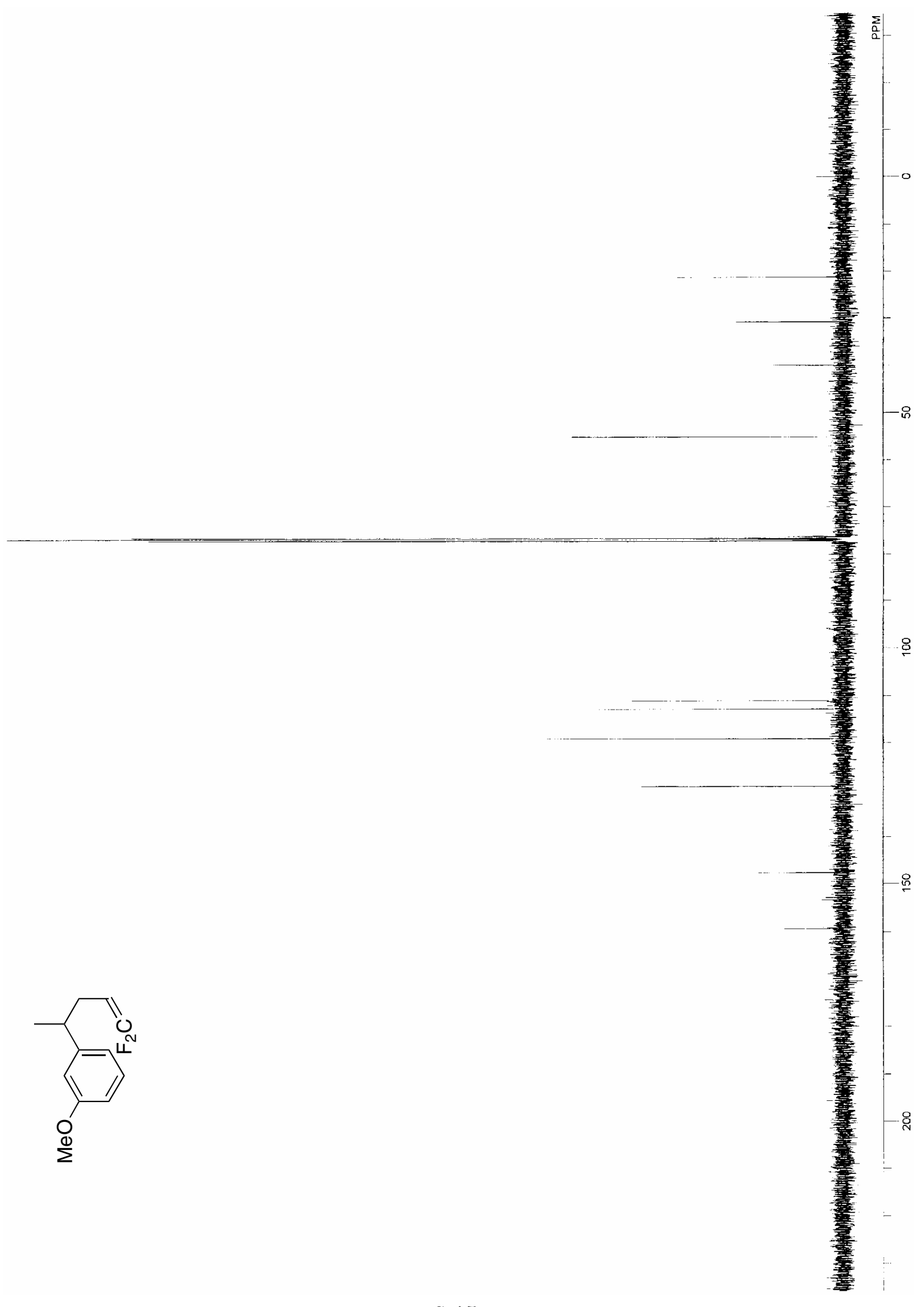

S-15 


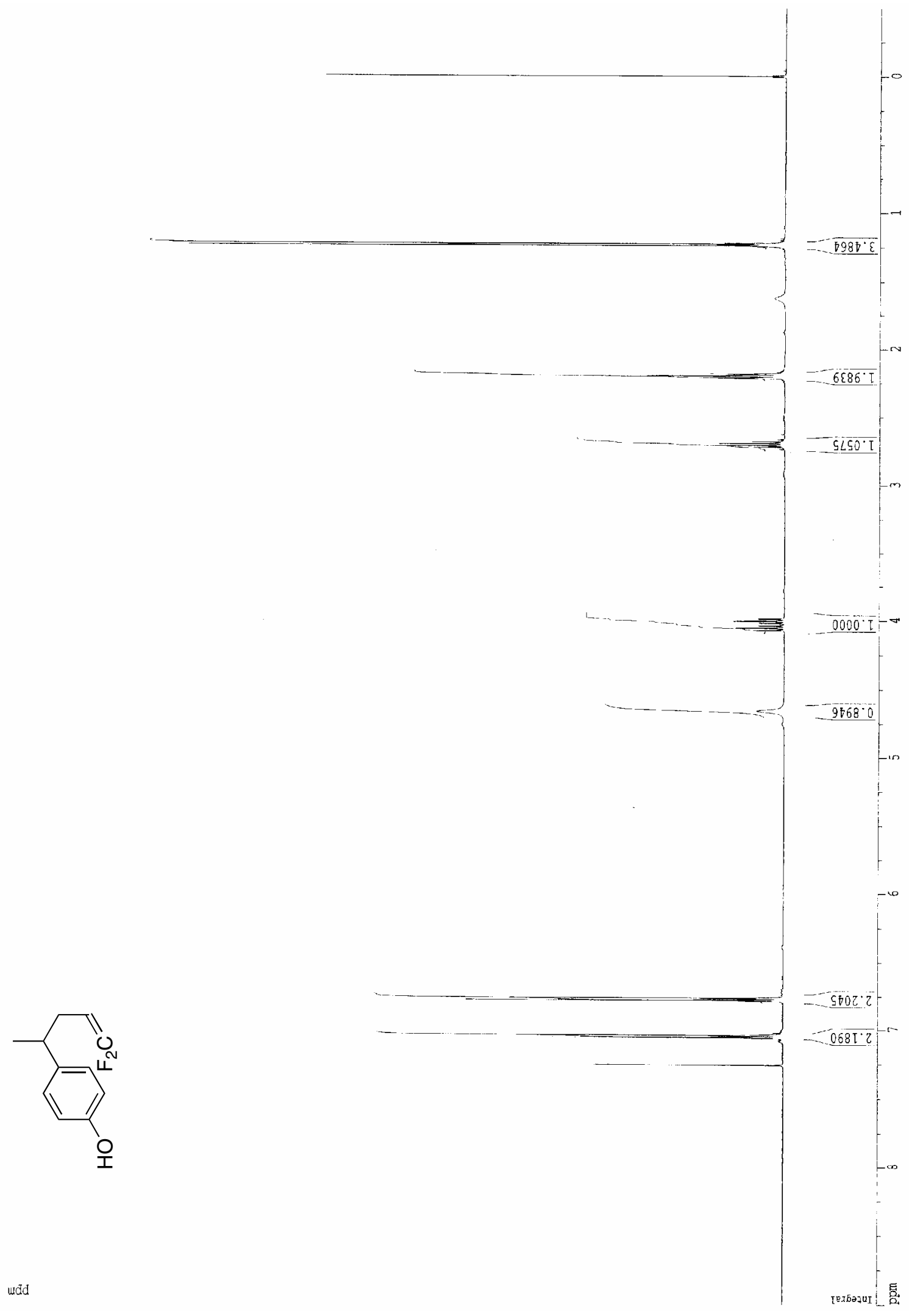

S-16 


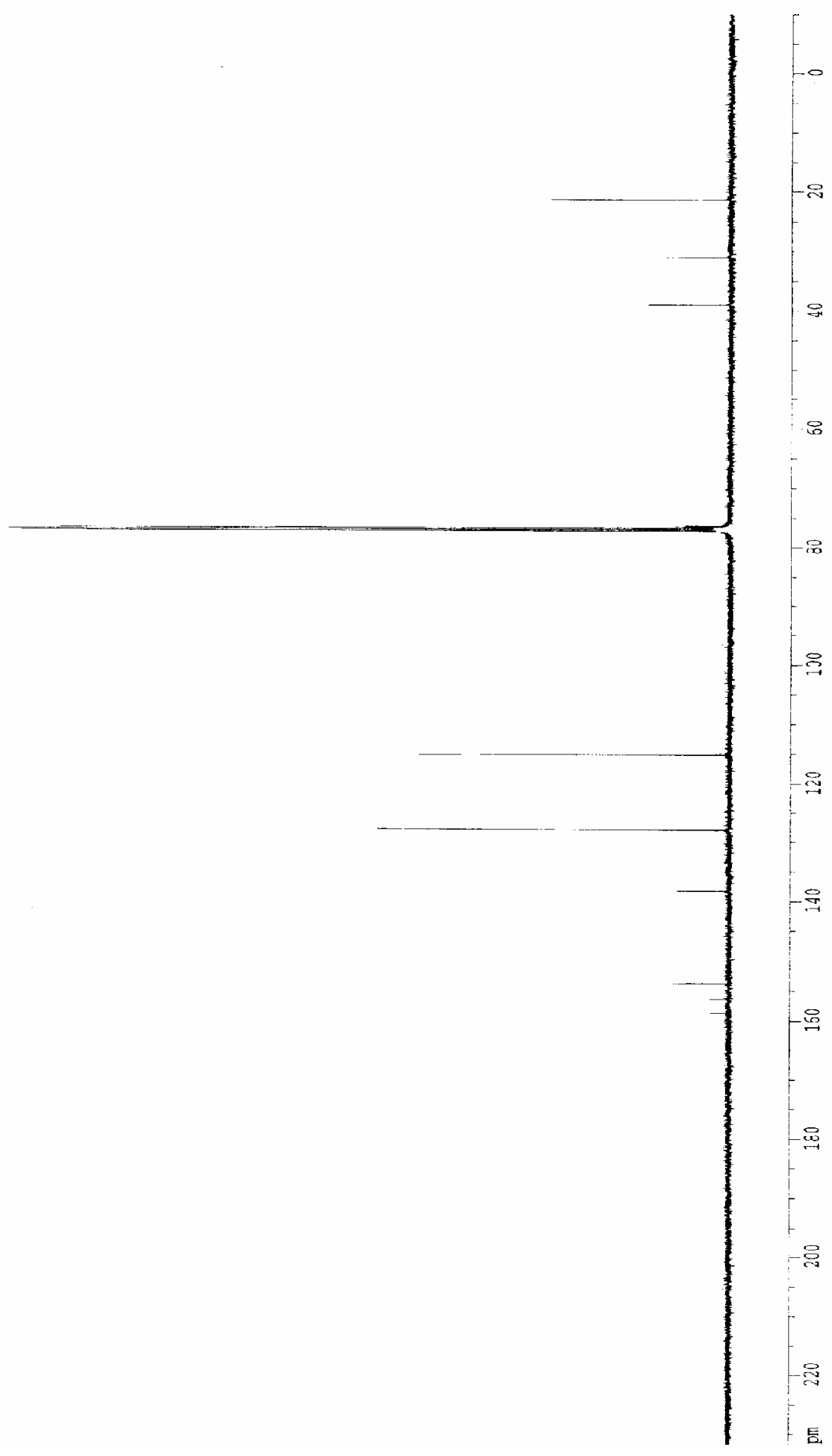




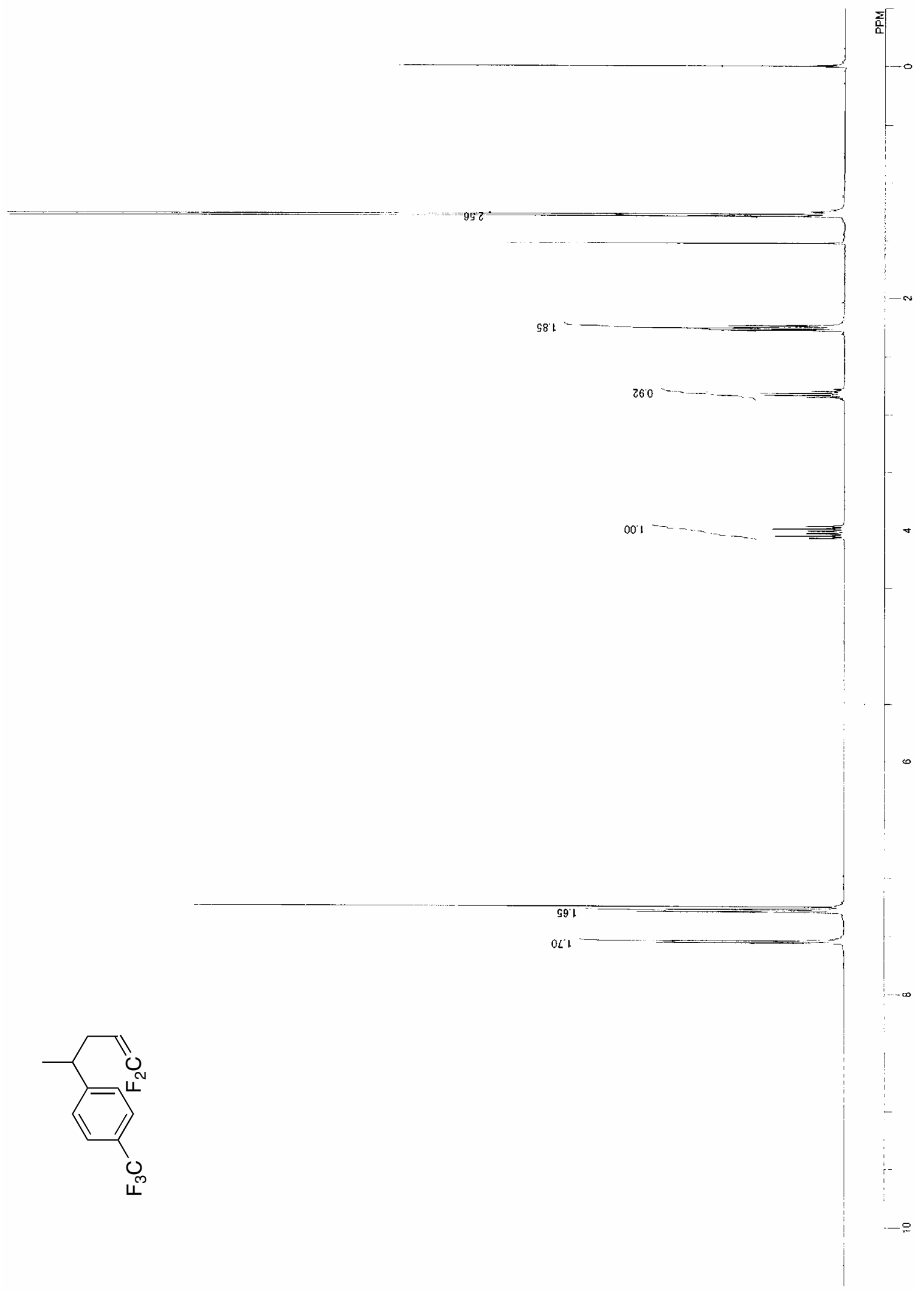

S-18 


$$
1
$$




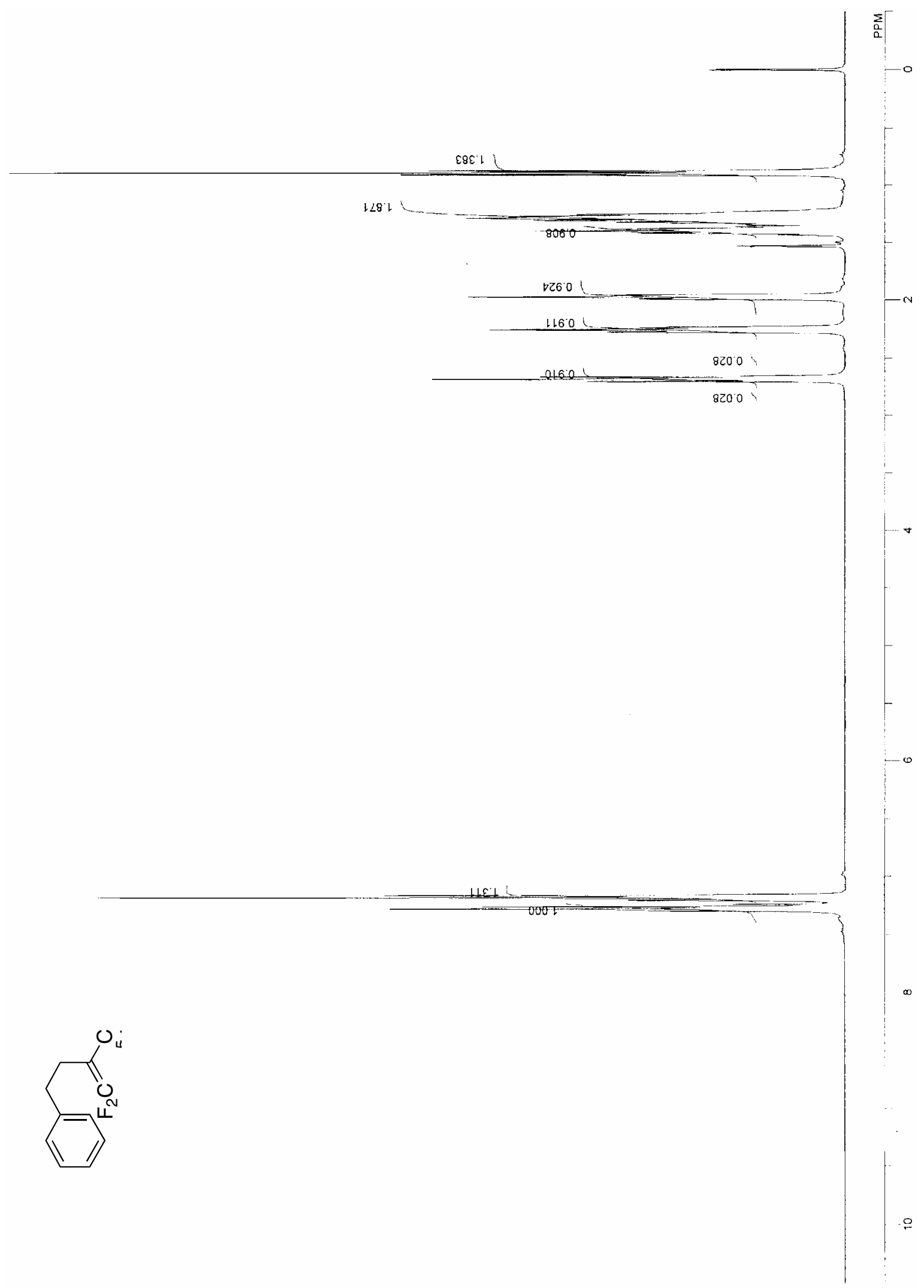




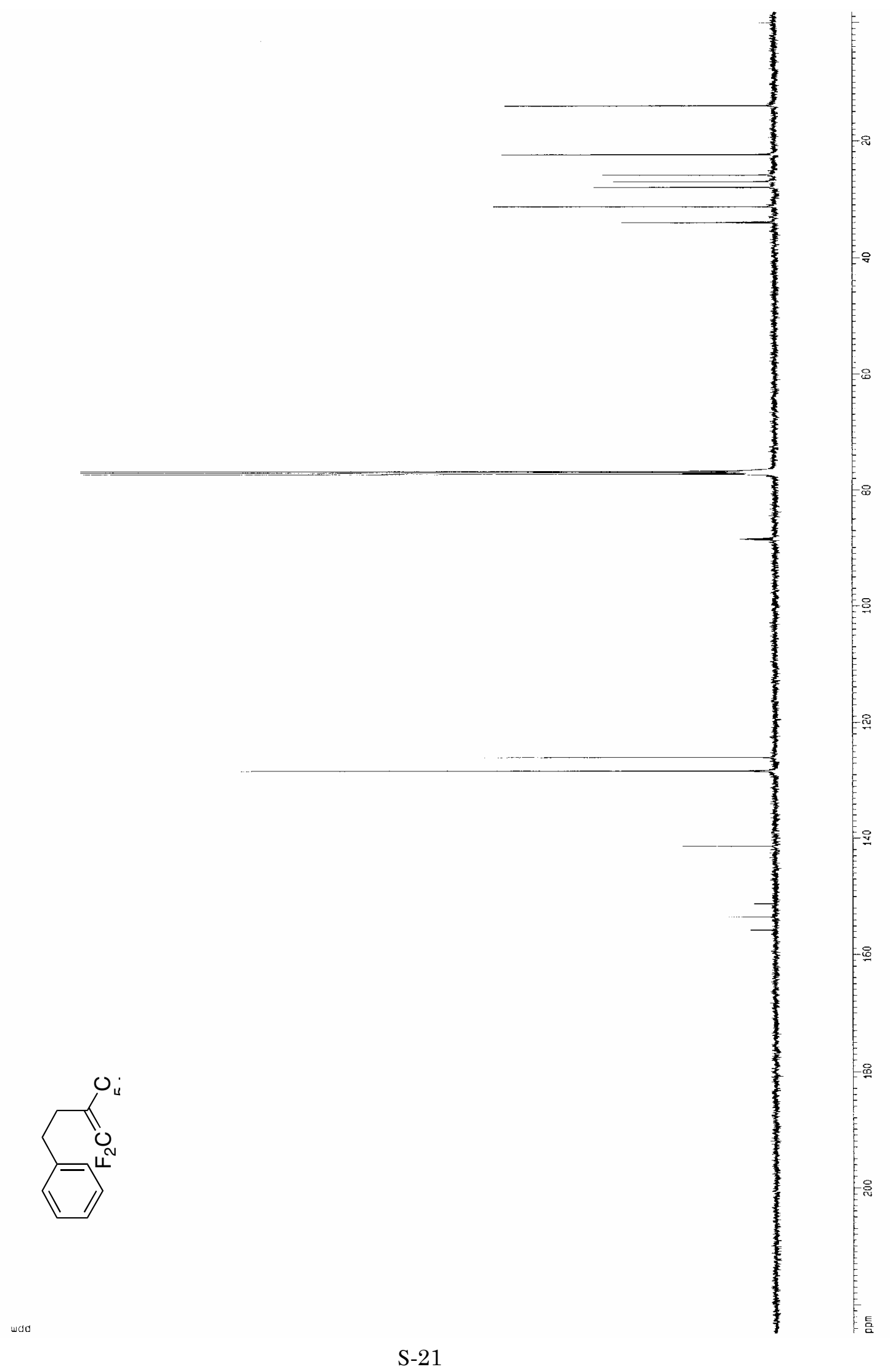




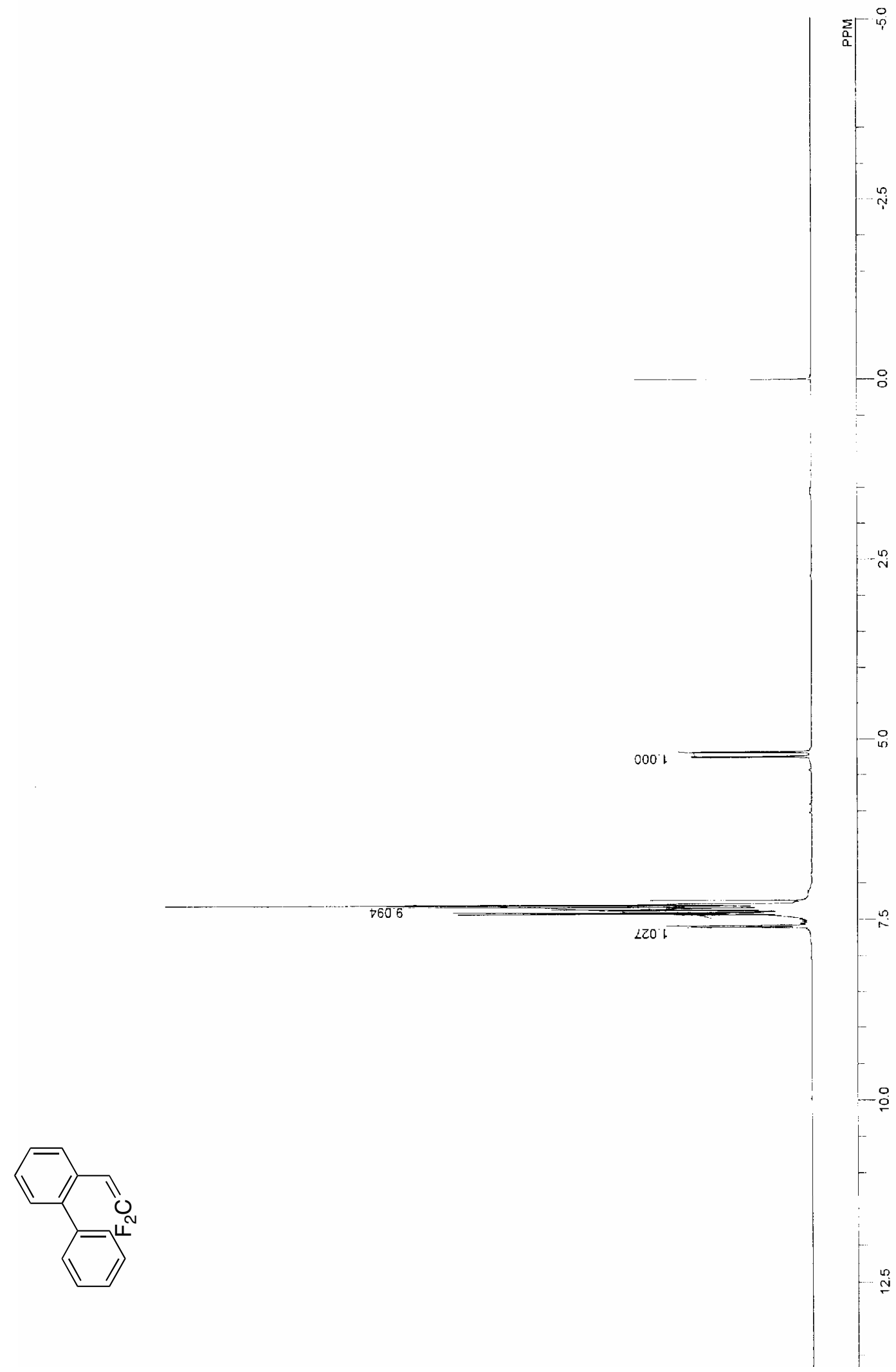




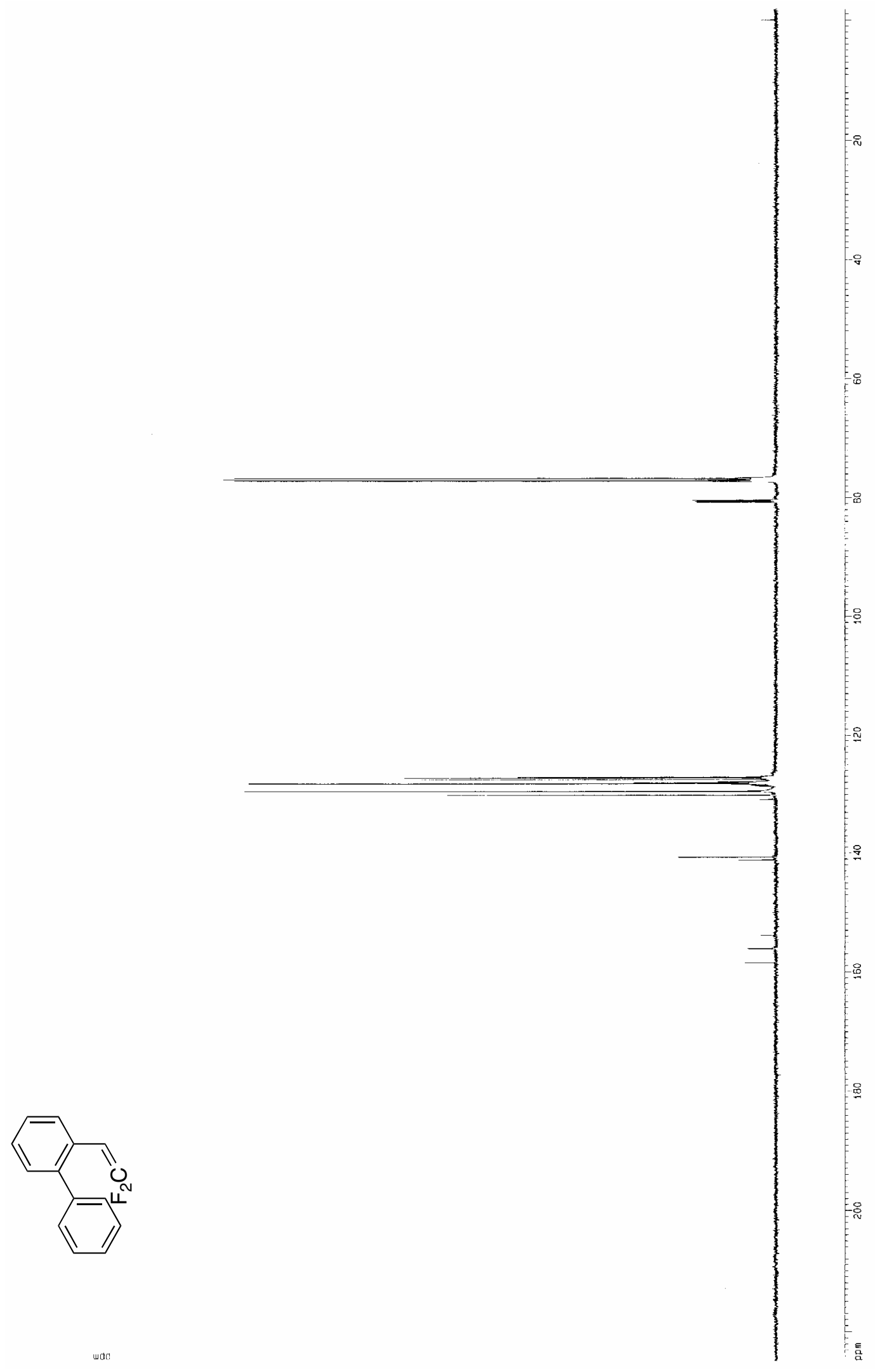




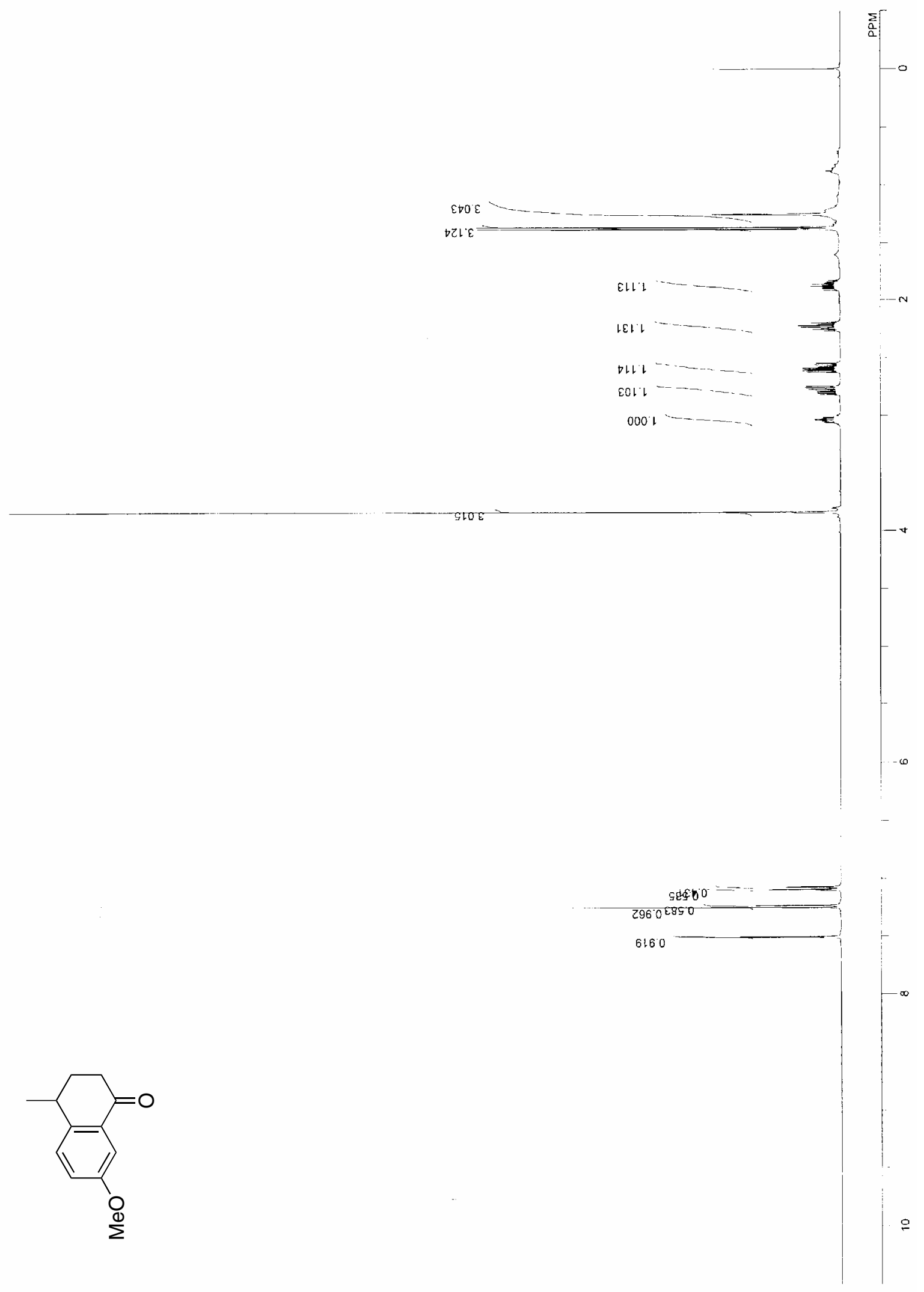




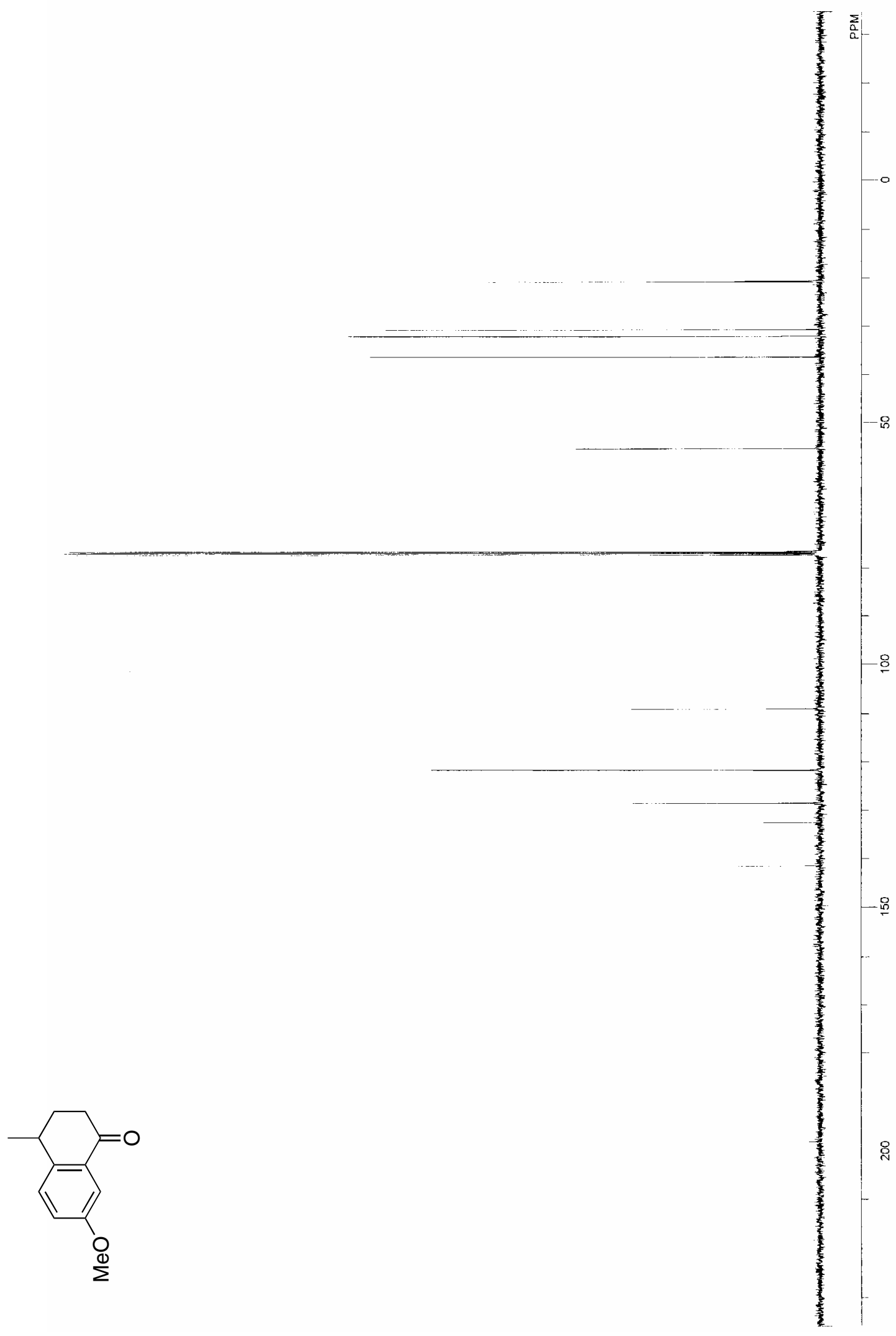

S-25 


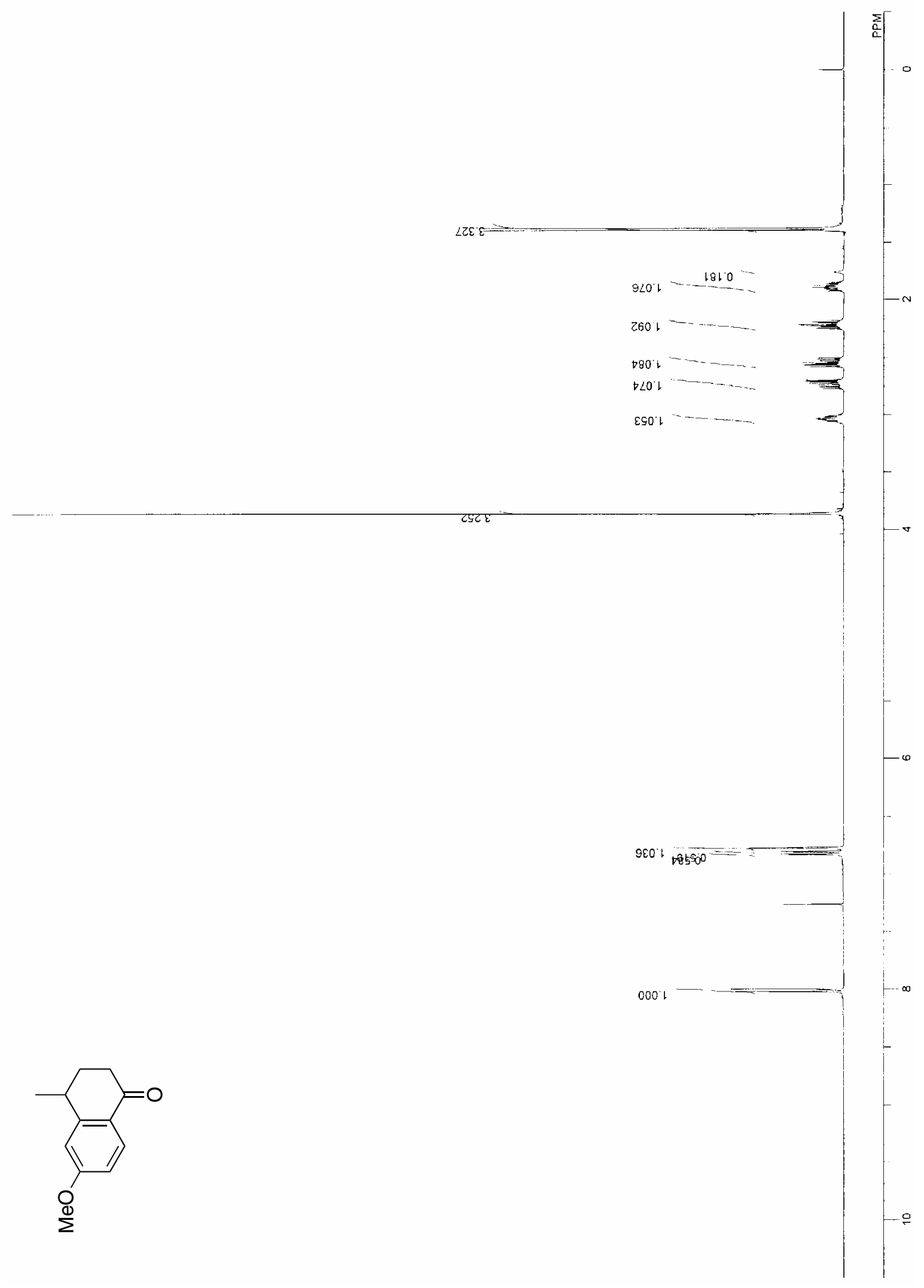




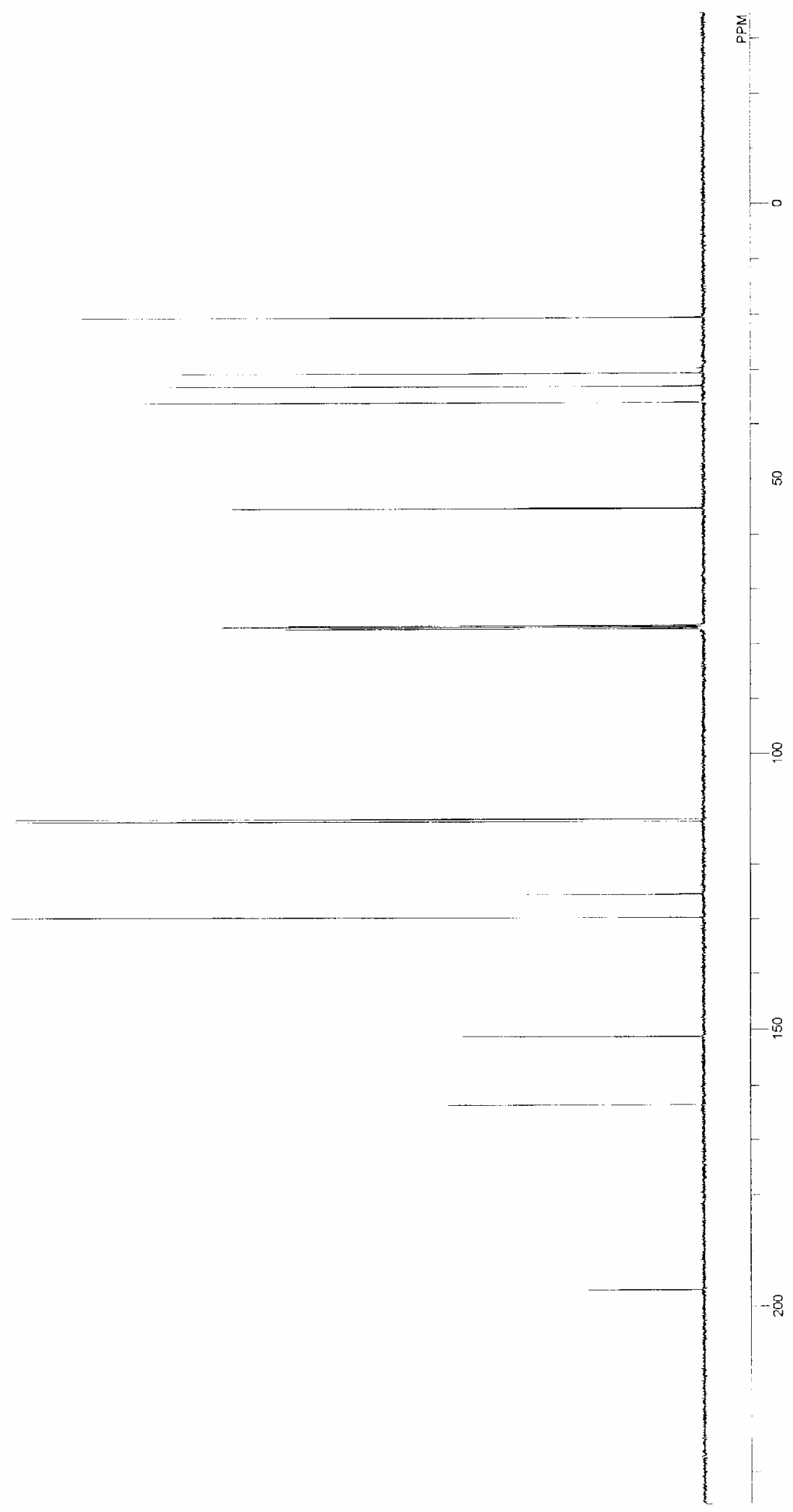




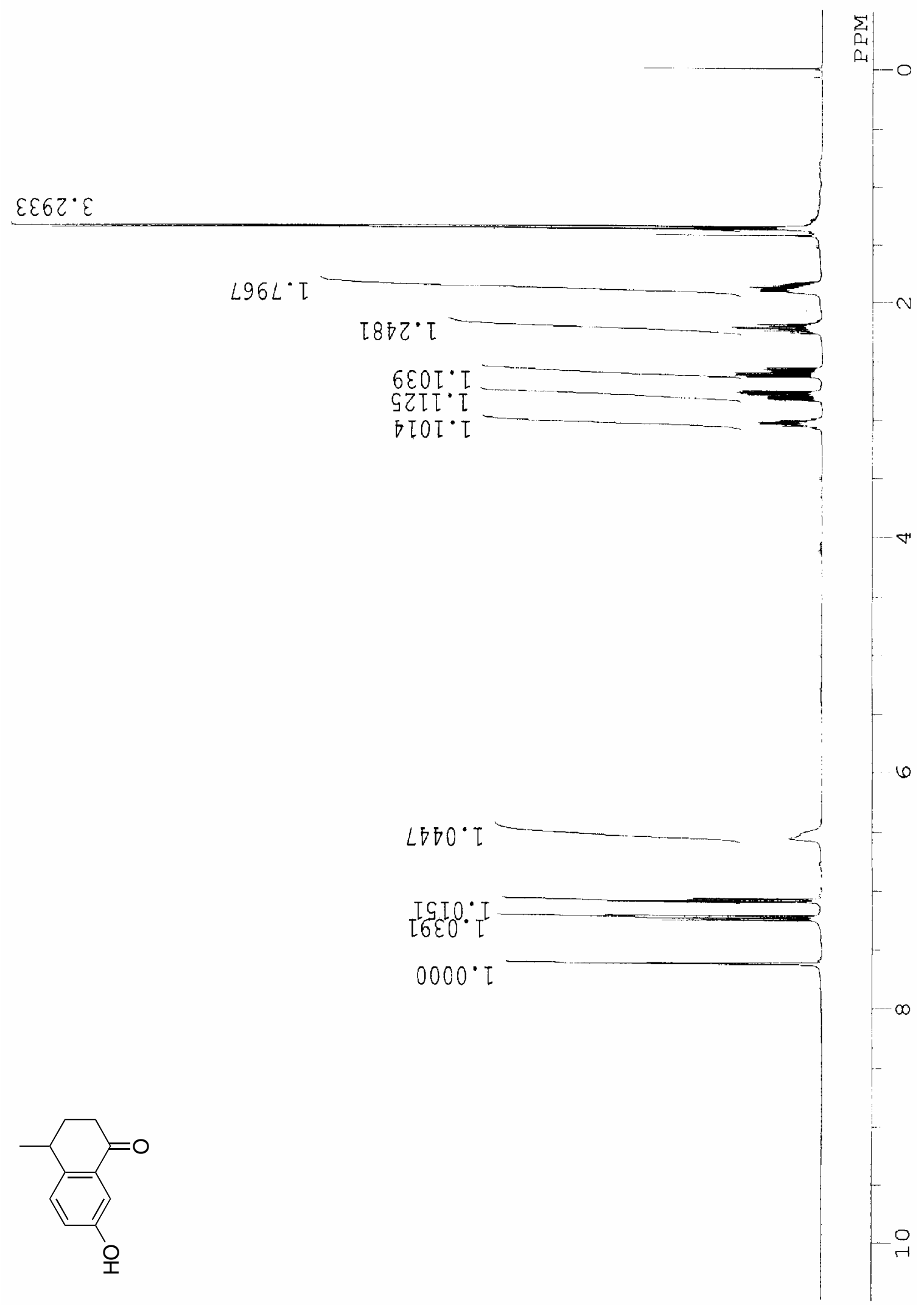

S-28 


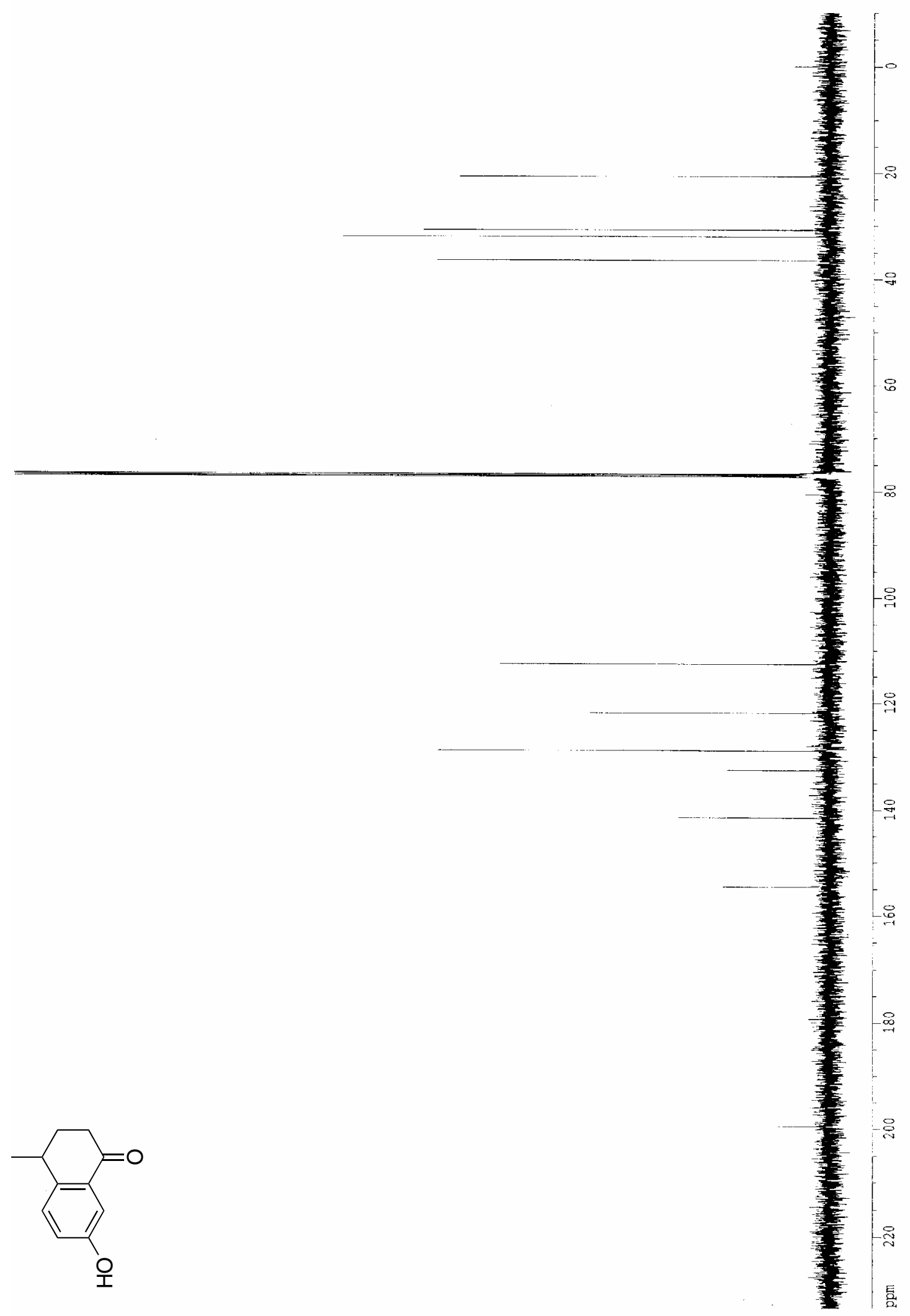

S-29 


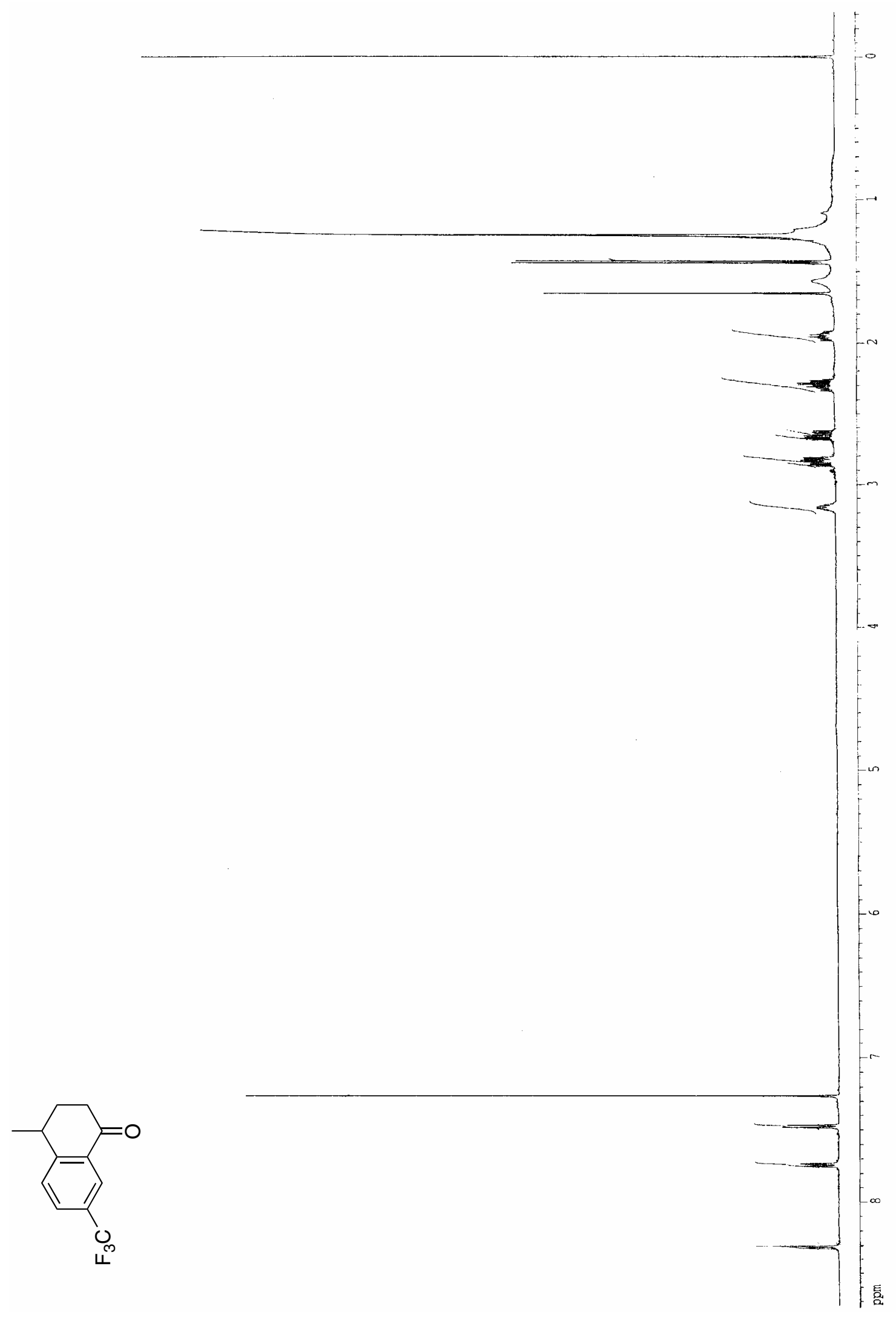




$$
-1
$$




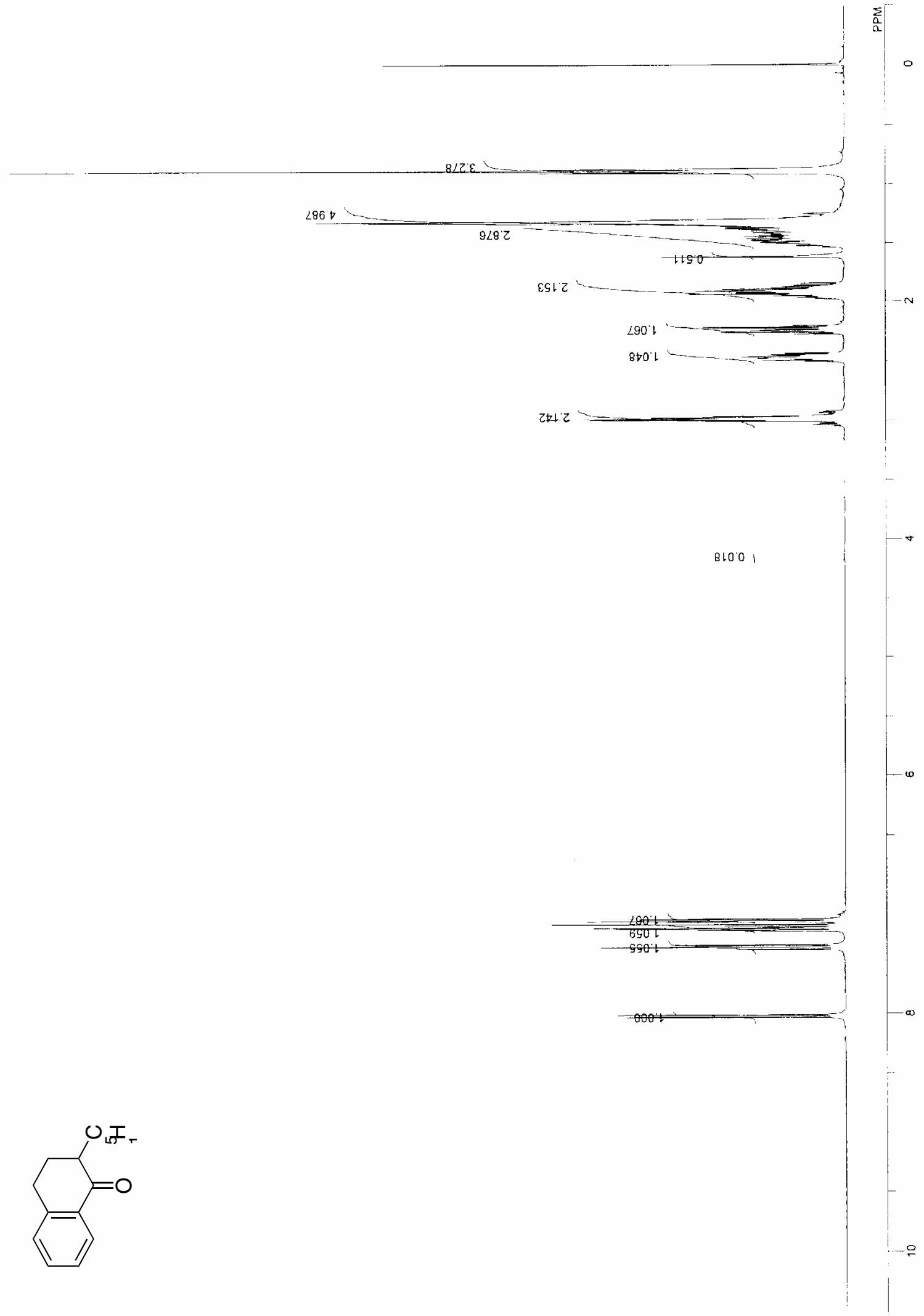




$$
y
$$




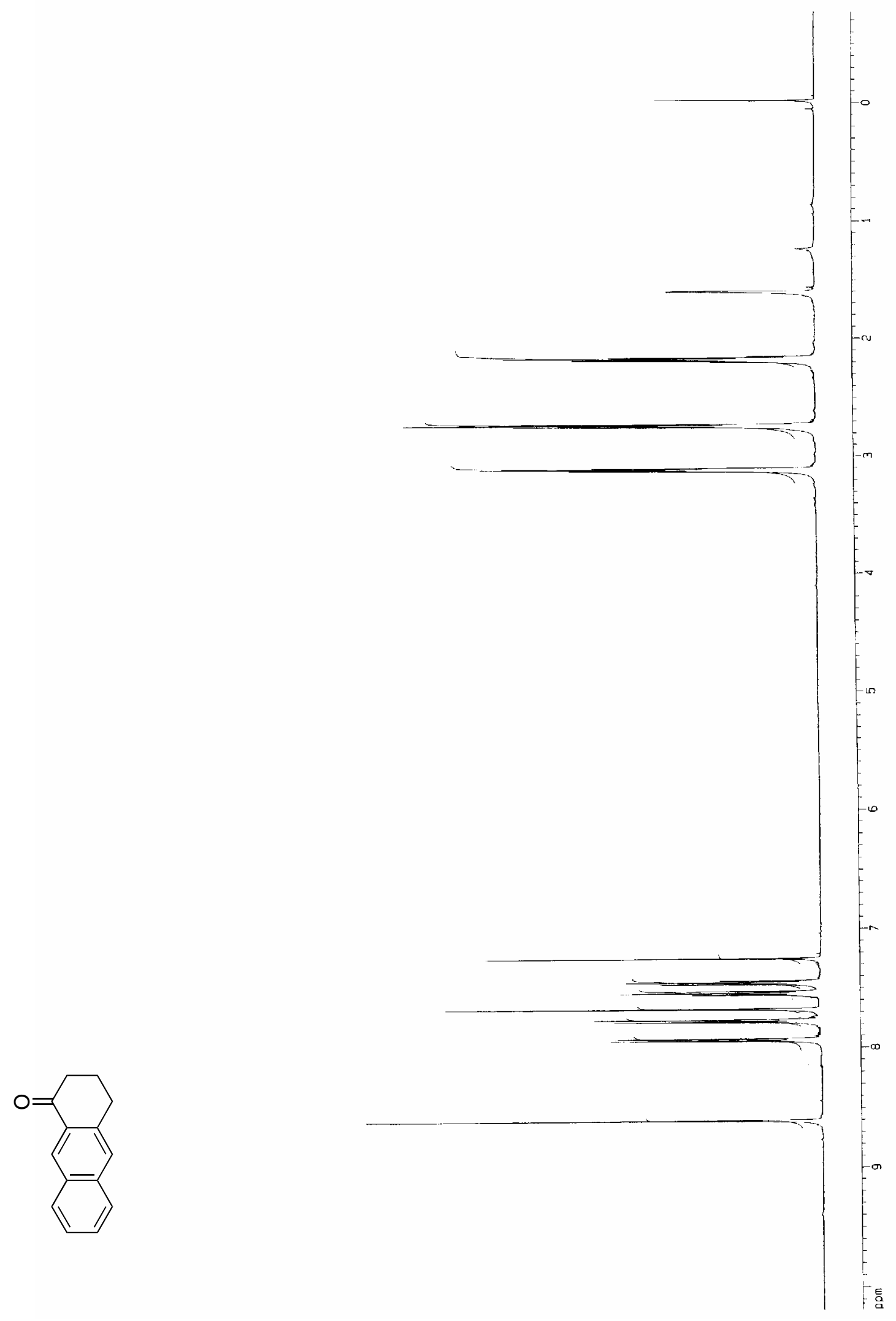

S-34 


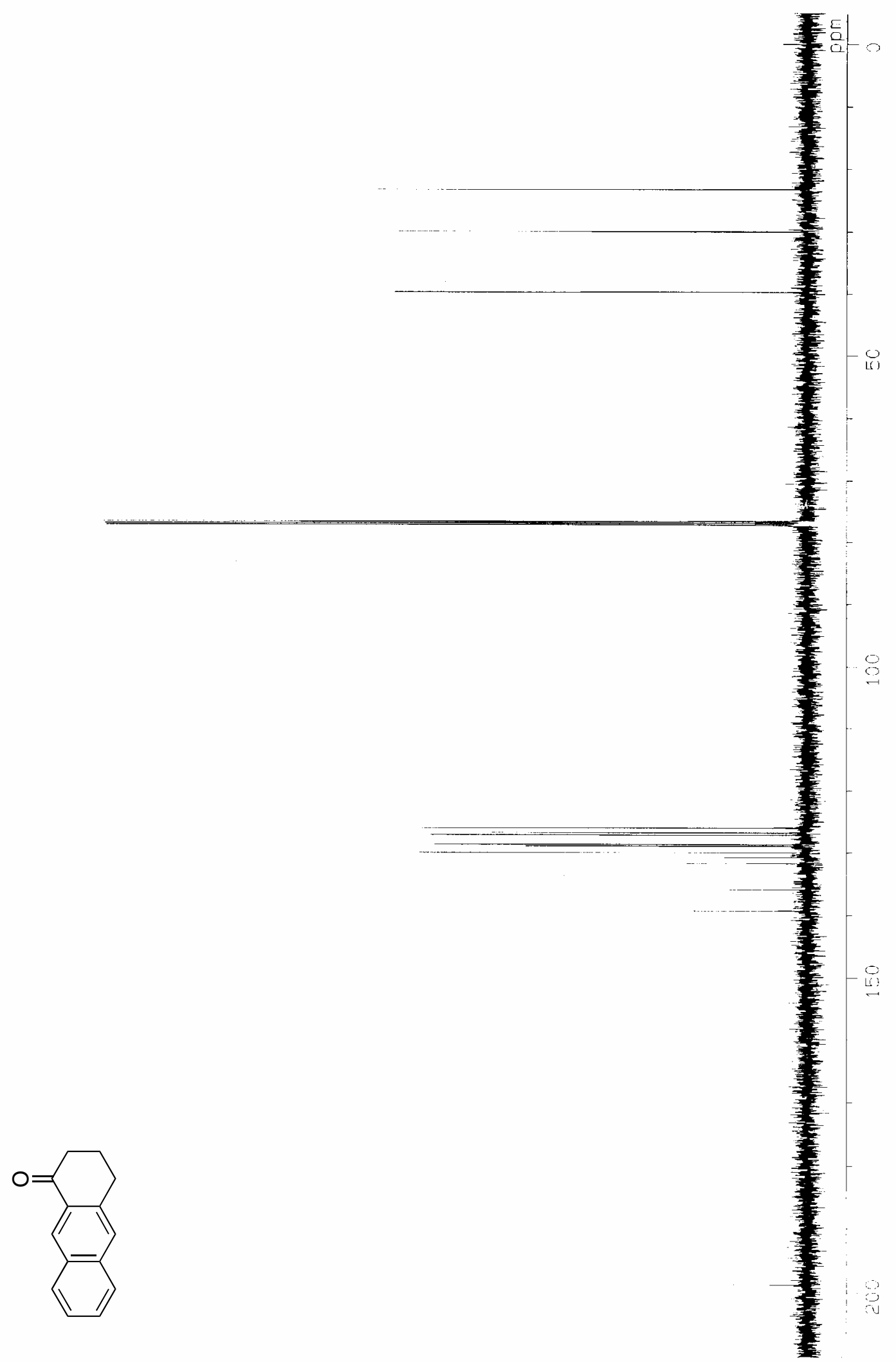

S-35 


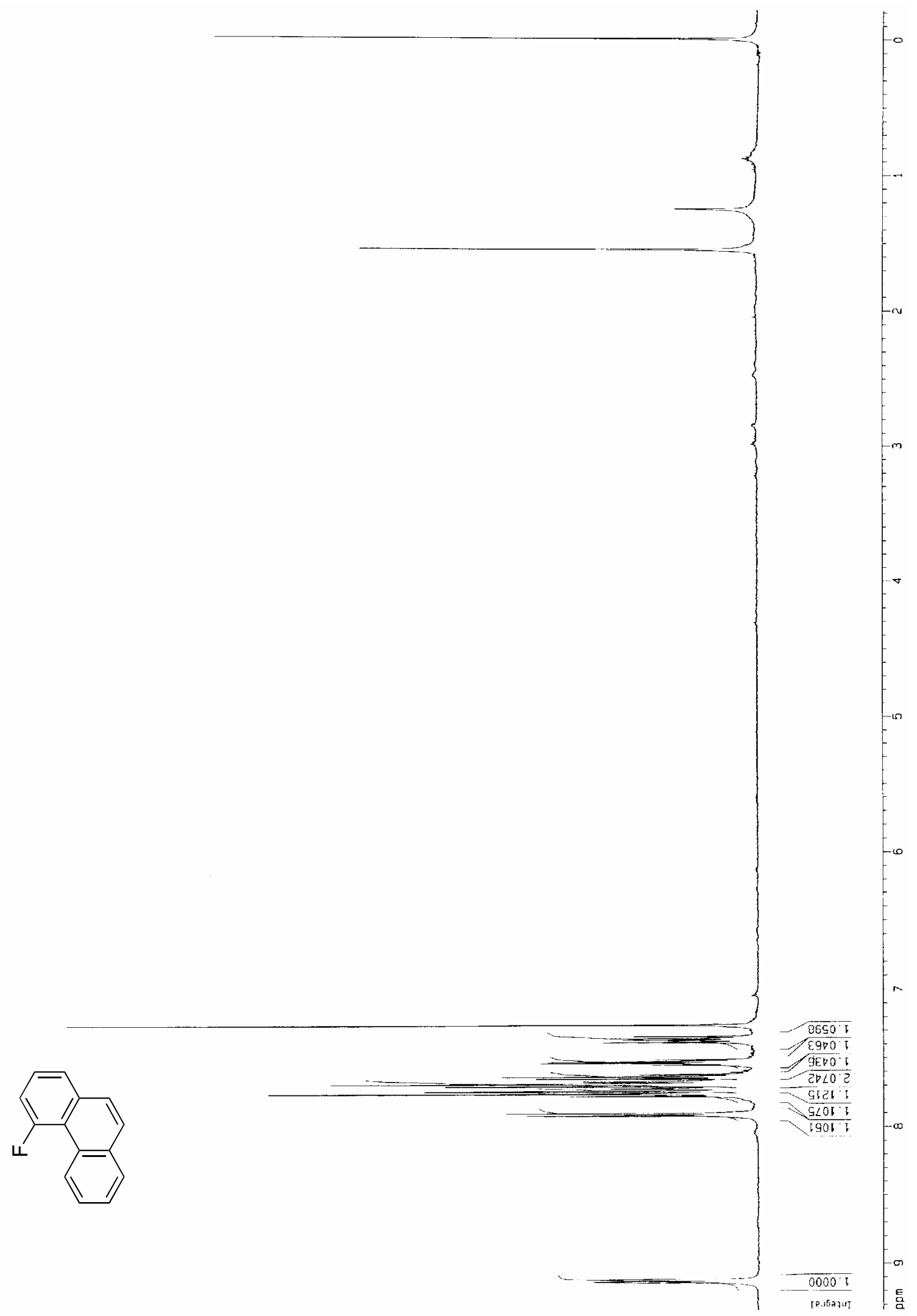




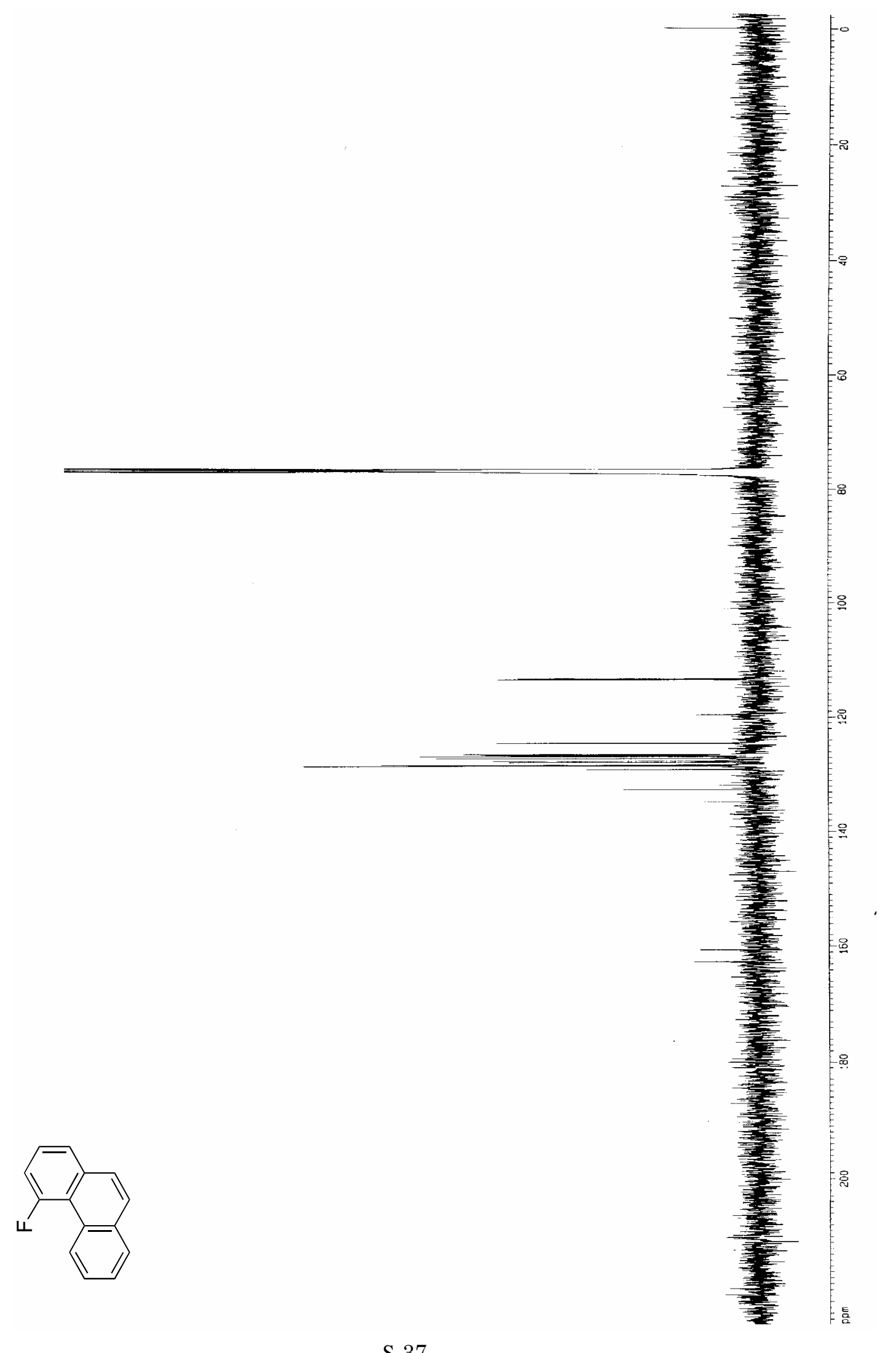

S-37 


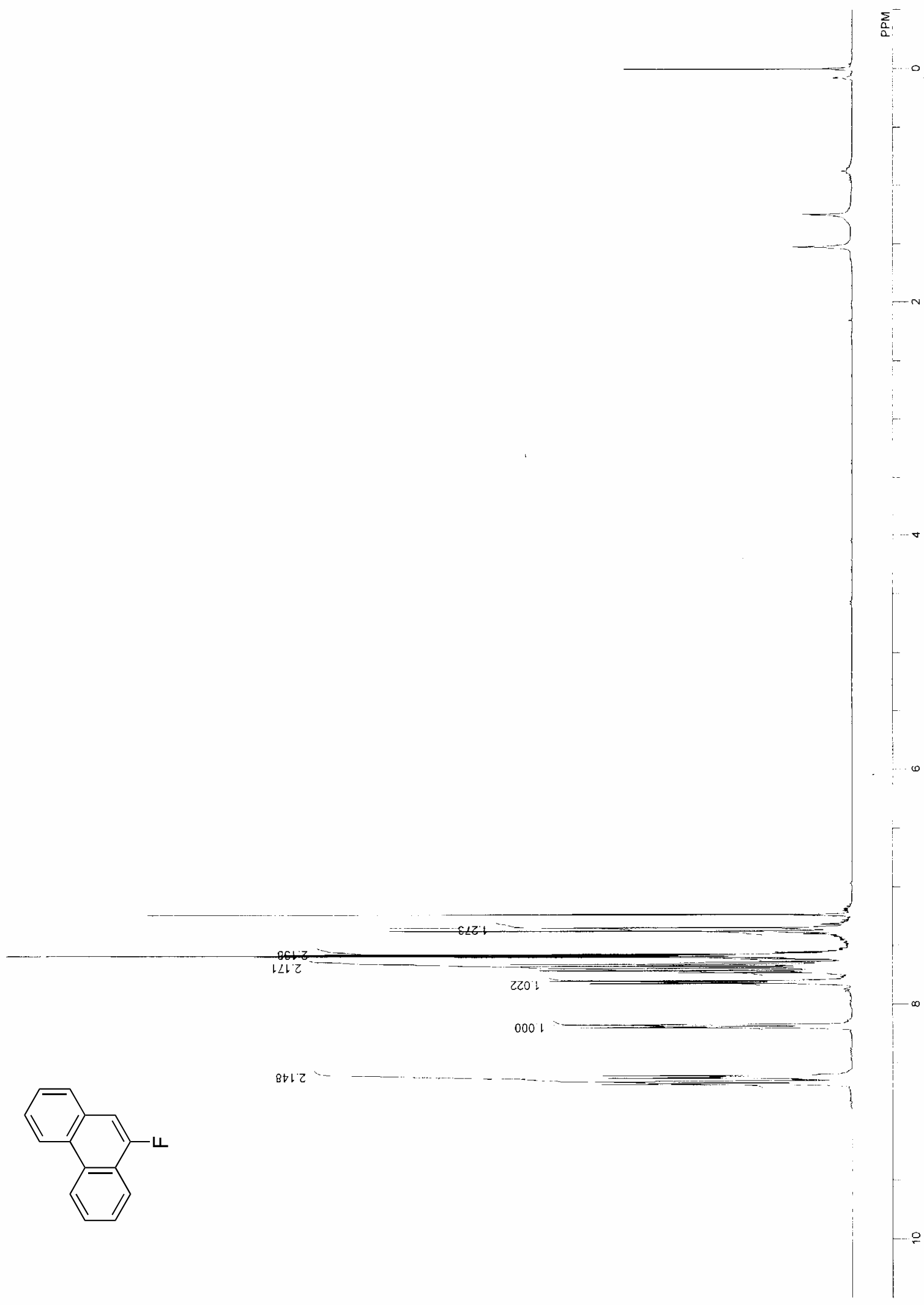

S-38 


$$
A
$$




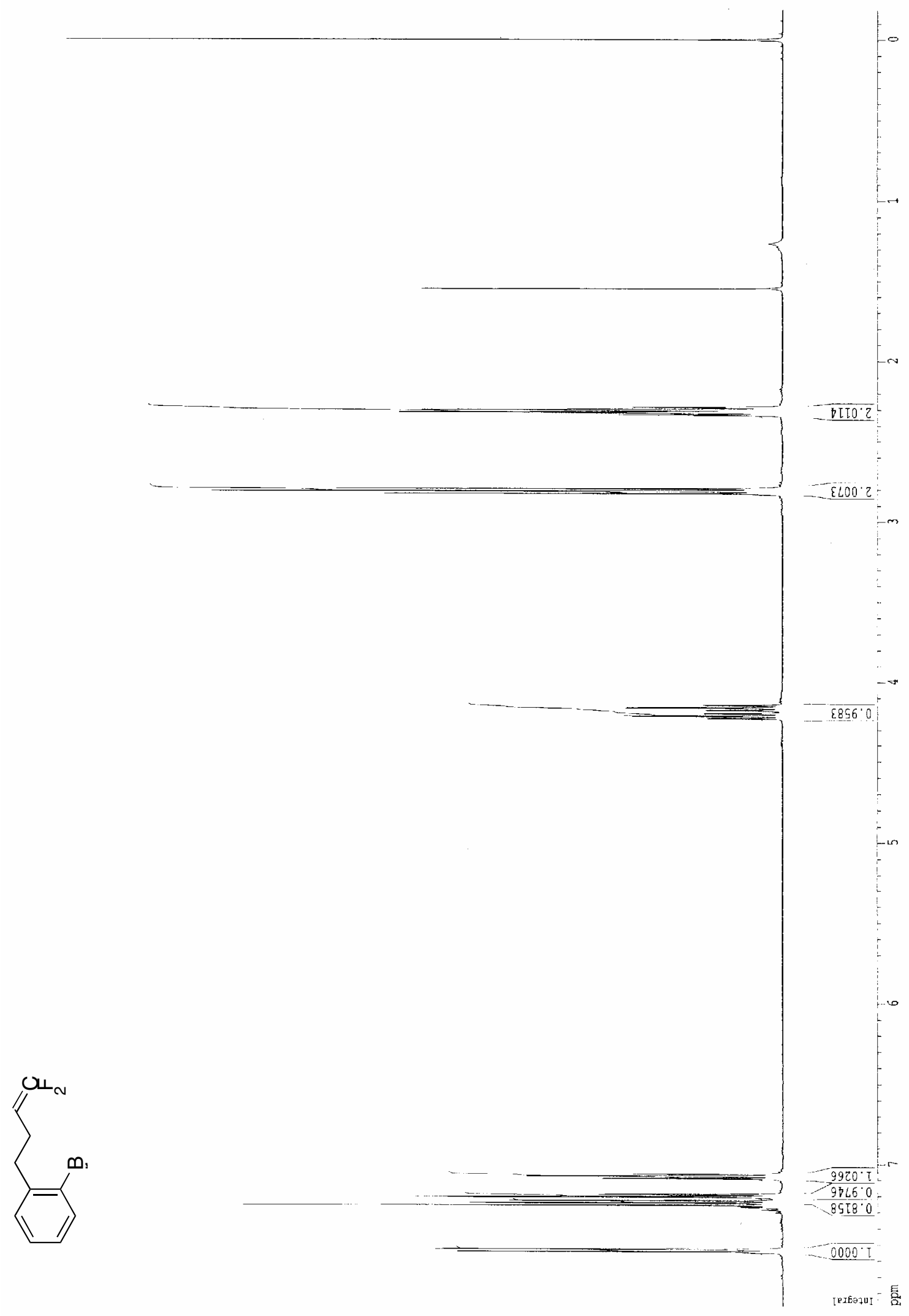

S-40 


$$
1
$$




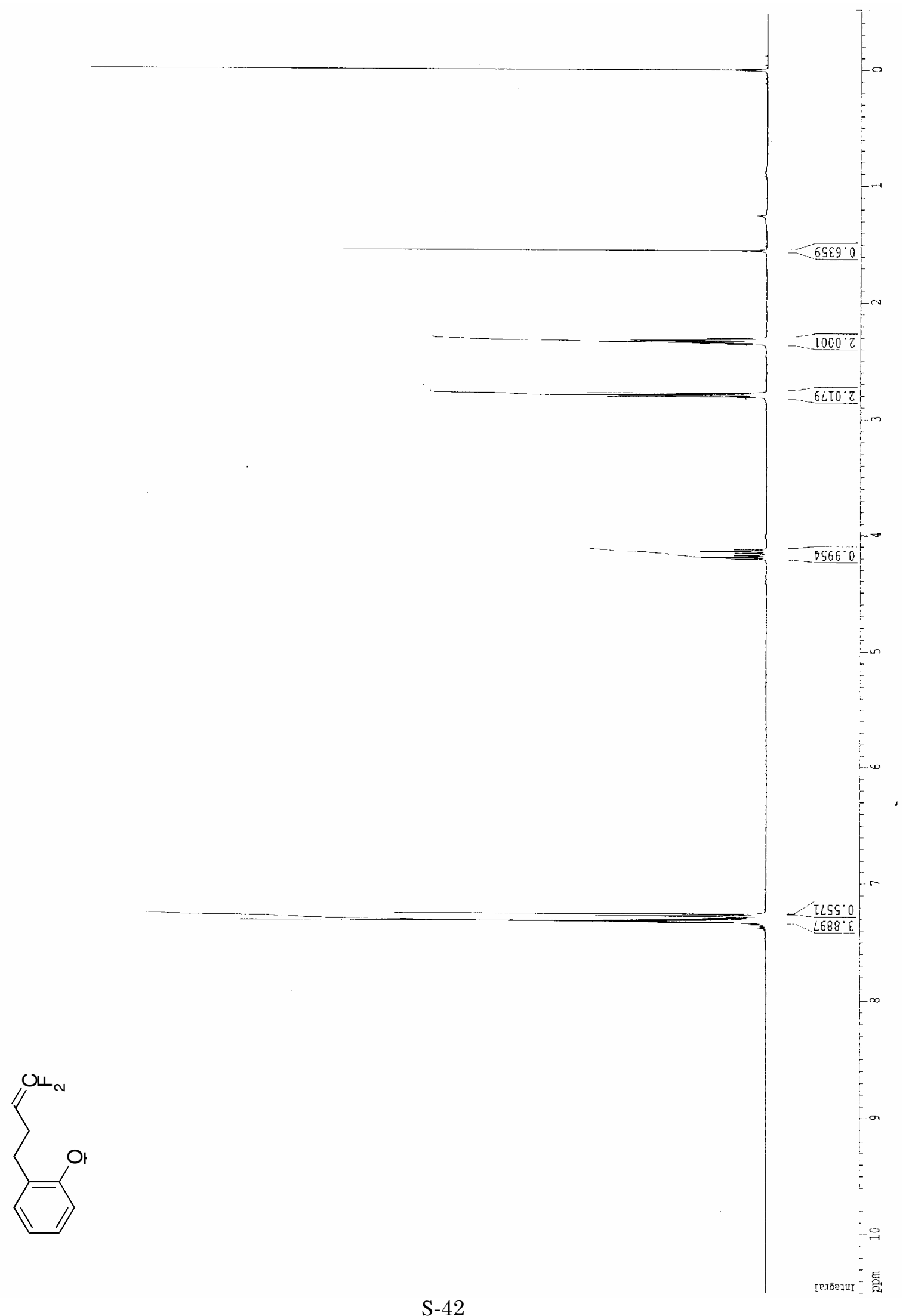




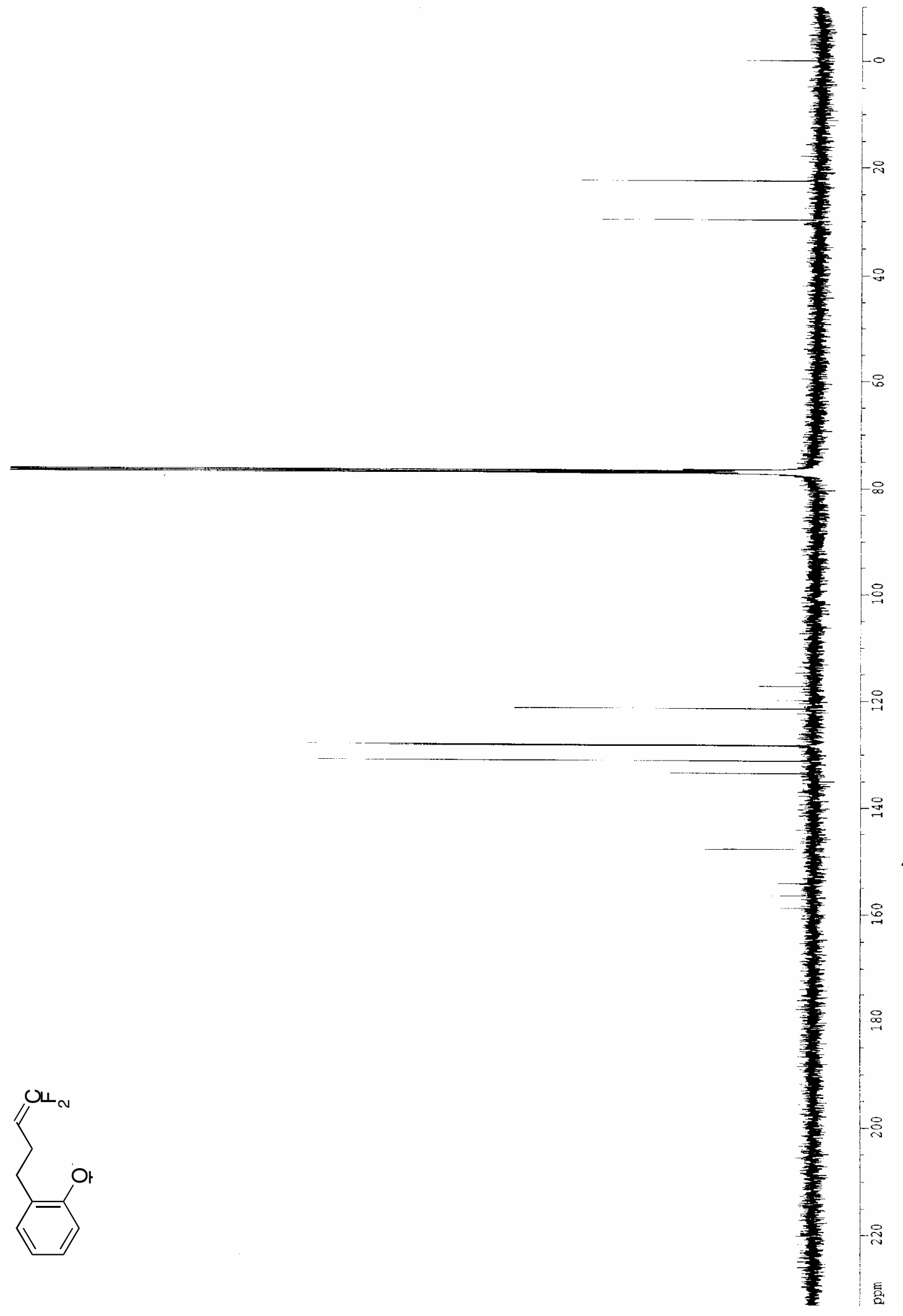

S-43 


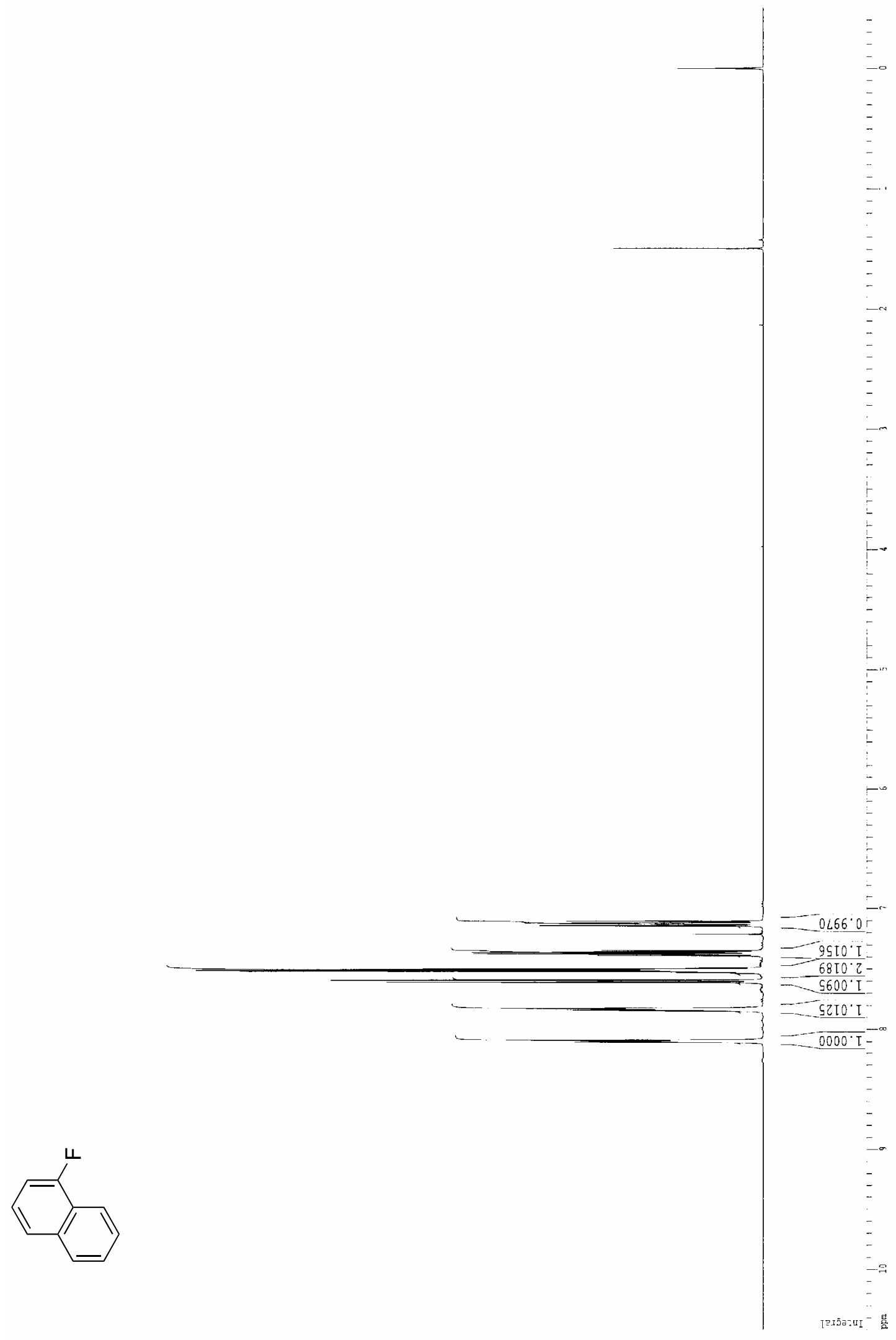

S-44 


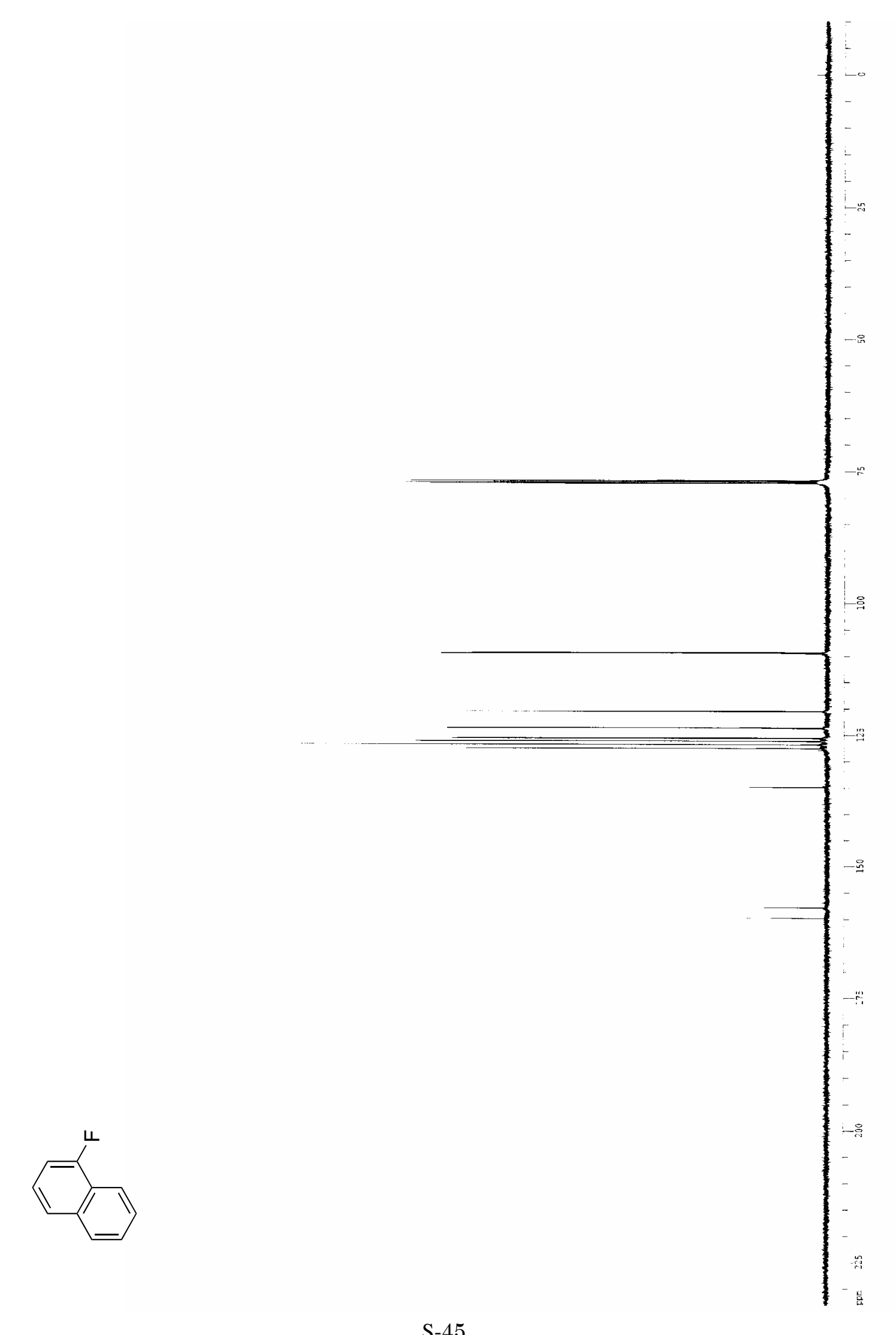




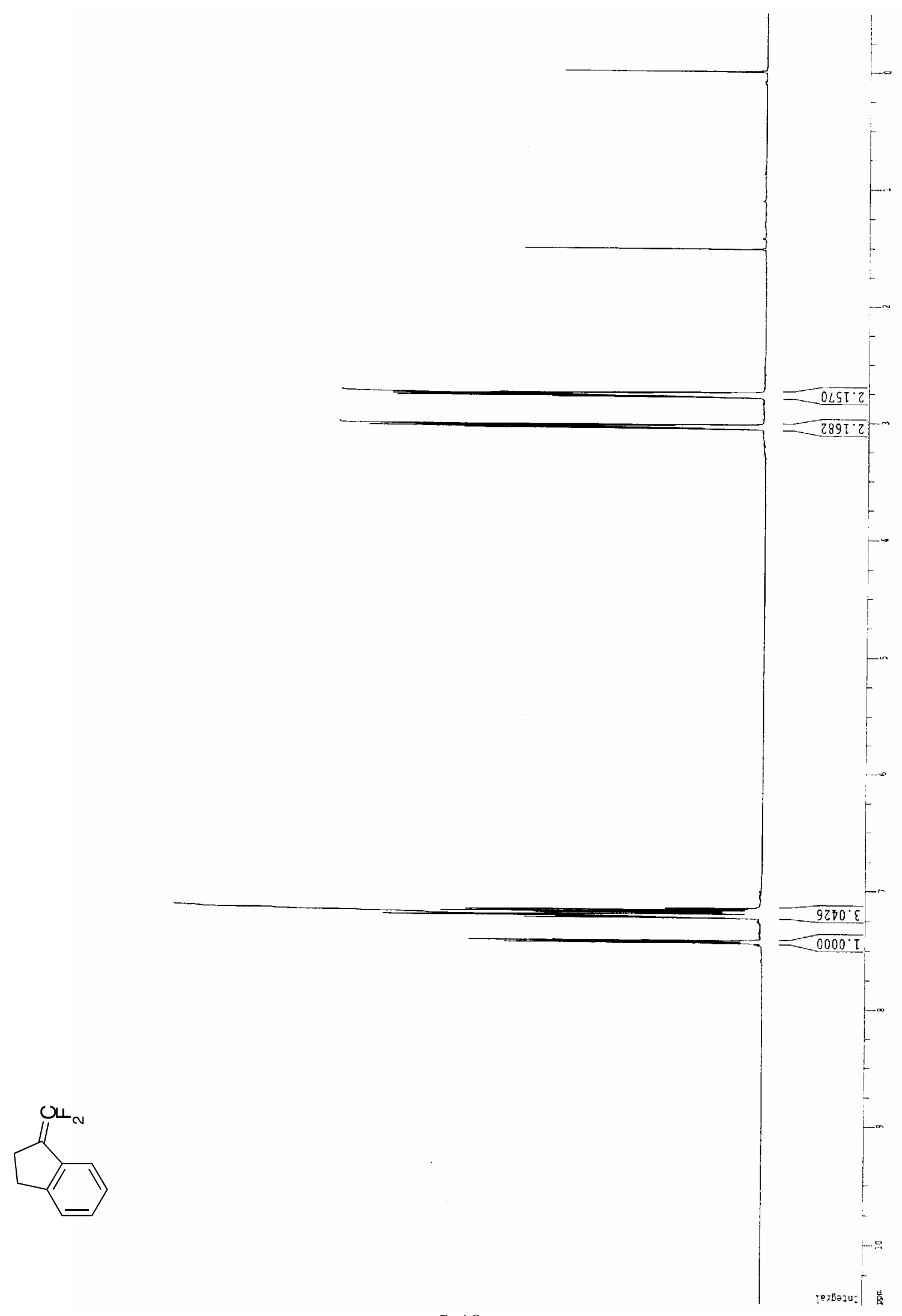

S-46 


$$
\exists
$$

